Check for updates

Cite this: Chem. Sci, 2022, 13, 2824

๑ All publication charges for this article have been paid for by the Royal Society of Chemistry

Received 31st October 2021 Accepted 31st January 2022

DOI: $10.1039 / \mathrm{d} 1 \mathrm{sc} 06015 \mathrm{e}$

rsc.li/chemical-science

\section{Bridging electrocatalyst and cocatalyst studies for solar hydrogen production via water splitting}

\author{
Masaki Saruyama, (D) * Christian Mark Pelicano (D) and Toshiharu Teranishi (D) *
}

Solar-driven water-splitting has been considered as a promising technology for large-scale generation of sustainable energy for succeeding generations. Recent intensive efforts have led to the discovery of advanced multi-element-compound water-splitting electrocatalysts with very small overpotentials in anticipation of their application to solar cell-assisted water electrolysis. Although photocatalytic and photoelectrochemical water-splitting systems are more attractive approaches for scaling up without much technical complexity and high investment costs, improving their efficiencies remains a huge challenge. Hybridizing photocatalysts or photoelectrodes with cocatalysts has been an effective scheme to enhance their overall solar energy conversion efficiencies. However, direct integration of highly-active electrocatalysts as cocatalysts introduces critical factors that require careful consideration. These additional requirements limit the design principle for cocatalysts compared with electrocatalysts, decelerating development of cocatalyst materials. This perspective first summarizes the recent advances in electrocatalyst materials and the effective strategies to assemble cocatalyst/photoactive semiconductor composites, and further discusses the core principles and tools that hold the key in designing advanced cocatalysts and generating a deeper understanding on how to further push the limits of water-splitting efficiency.

\section{Introduction}

Reducing the amount of $\mathrm{CO}_{2}$ emitted from burning fossil fuels is essential to mitigate global warming. ${ }^{1}$ To meet this challenge while addressing the growing global energy demand, it is becoming increasingly important to develop sustainable, carbon-neutral energy sources. ${ }^{2}$ Molecular hydrogen $\left(\mathrm{H}_{2}\right)$ is

Institute for Chemical Research, Kyoto University, Gokasho, Uji, Kyoto 611-0011, Japan.E-mail: saruyama@scl.kyoto-u.ac.jp; teranisi@scl.kyoto-u.ac.jp regarded as an ideal green fuel because it releases zero emissions and only produces water upon combustion. ${ }^{3}$ Therefore, $\mathrm{H}_{2}$ is expected to hold prime significance as a high-energy-density fuel in future energy systems. In fact, $\mathrm{H}_{2}$ fuel cells have been implemented to power vehicles with advanced $\mathrm{H}_{2}$ transportation technologies. ${ }^{4}$

Although hydrogen is the most abundant element on earth, the dihydrogen molecule rarely exists in nature; therefore, $\mathrm{H}_{2}$ must be produced artificially. Currently, steam reforming is the preferable method for producing commercial $\mathrm{H}_{2}$; however,

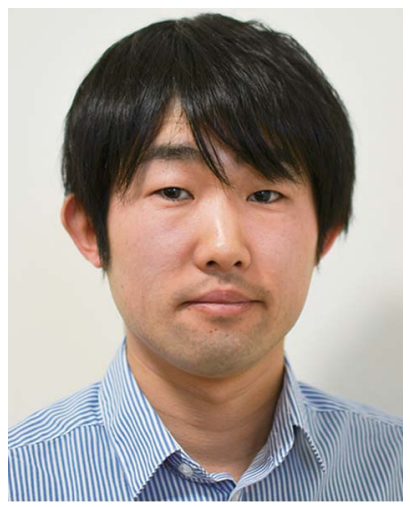

Masaki Saruyama is a Programspecific assistant professor in Institute for Chemical Research, Kyoto University. He received his $\mathrm{PhD}$ in Science from Tsukuba University in 2011 under the supervision of Prof. Toshiharu Teranishi. He joined Kyoto University in 2015 after working for Mitsui Chemicals, Inc. His research interests involve development of inorganic nanoparticles for photocatalytic water splitting, ion exchange reaction of ionic nanocrystals, and self-assembly of nanoparticles.

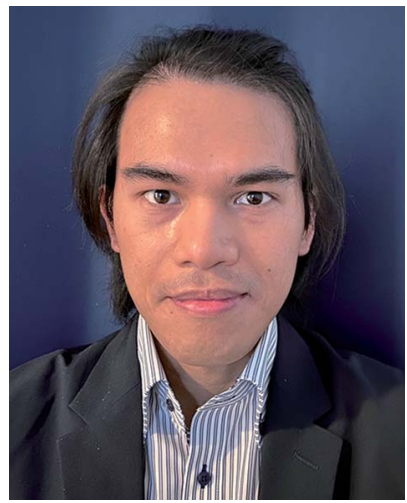

Christian Mark Pelicano received his $P h D$ in 2019 from the Nara Institute of Science and Technology in Japan. He is currently working as a postdoctoral fellow in Kyoto University under the supervision of Prof. Toshiharu Teranishi to develop multi-metallic cocatalysts for photocatalytic water splitting. His research interests are centered on the synthesis and design of functional nanomaterials for solar energy conversion especially in the area of hybrid solar cells and photo/electrocatalytic hydrogen production. 
a substantial amount of energy is required to drive this process and $\mathrm{CO}_{2}$ is emitted as a byproduct. ${ }^{5}$ Recently, sunlight-driven water splitting has emerged as an attractive approach for green and sustainable $\mathrm{H}_{2}$ production. ${ }^{6}$ Among solar-hydrogen technologies, water electrolysis using electricity generated from solar cells is considered to be the most advanced pathway. ${ }^{7}$ Combining a solar cell with an electrocatalyst (EC)-loaded electrode can promote water splitting, reaching $>30 \%$ solar-tohydrogen efficiency (STH) using an InGaP/GaAs/GaInNAsSb triple-junction solar cell. ${ }^{\mathbf{s}}$

Thermodynamically, the reduction and oxidation of water start at $0 \mathrm{~V}_{\mathrm{RHE}}$ and $+1.23 \mathrm{~V}_{\mathrm{RHE}}$, respectively, meaning that the overall water-splitting reaction can start from $1.23 \mathrm{~V}$. However, the activation energy for each half-reaction contributes to an overpotential, which requires an additional voltage (hundreds of millivolts) to overcome and drive the water-splitting process. ${ }^{9}$ In practical applications, ECs are employed to reduce this overpotential, thereby improving the STH.

To date, the high cost of device manufacturing has hindered the practical implementation of solar cell-assisted $\mathrm{H}_{2}$-production devices. However, the direct decomposition of water through photocatalysis represents a promising alternative approach owing to its technical simplicity and low associated investment costs. ${ }^{10,11}$ Scaling up a photocatalytic system is also relatively much easier because water splitting can proceed by simply immersing semiconductor photocatalyst (PC) powder in water under light irradiation. ${ }^{\mathbf{1 2}}$ Recently, a large-scale experiment (100 $\mathrm{m}^{2}$ scale) demonstrated that immobilizing powdered

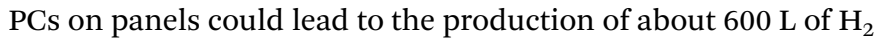
on a sunny day. ${ }^{13}$ Such photoactive semiconductors can also be used as light-absorbing layer of photoelectrodes (PEs) for photoelectrochemical (PEC) water-splitting cells. ${ }^{14}$ These electrodes are usually placed in separate compartments which are electrically connected through an external circuit. Although this configuration makes PEC systems more complex in terms of design, higher STH efficiencies have been achieved due to easier product collection and elimination of potential back-reactions. ${ }^{15}$ For example, a tandem-type PEC cell reached an STH of

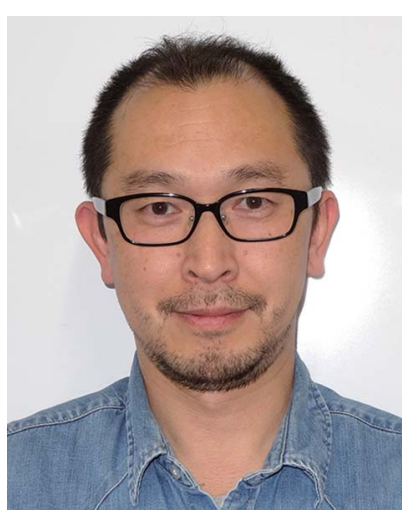

Toshiharu Teranishi is
a professor at Institute for
Chemical Research University. He received his $P h D$ from The University of Tokyo under the direction of Prof. Naoki Toshima in 1994, and spent seven and a half years at Japan Advanced Institute of Science and Technology as an Assistant Professor and an Associate Professor. In 2004, He moved to University of Tsukuba as a Full Professor, and moved to Kyoto University in 2011. Current research interests include precise structural control of inorganic nanomaterials and structure-specific functions for high-performance devices and photo-energy conversion.
$>7 \%$, which far exceeds current STH values for PC systems. ${ }^{16}$ However, both PC and PEC systems still have large rooms to reach a target STH of $10 \%$ with a long-term durability for practical application. ${ }^{\mathbf{1 2}}$

To realize a higher water-splitting performance, substantial efforts have been mainly devoted to the development of semiconductors as efficient photoactive materials. ${ }^{\mathbf{1 0}}$ Cocatalysts (CCs), which are water-splitting catalysts coupled with PCs or PEs, also have been systematically studied as equally-important components in both PC and PEC systems. ${ }^{17}$ Because the semiconductor surface tends to have a weak driving force for redox reactions involving water, coupling with CCs can facilitate these redox reactions by lowering the activation energy barrier. ${ }^{\mathbf{1 7}}$ Specifically, charged-up CCs retain suitable steady-state potentials to drive the surface reactions by serving as trapping sites for photogenerated carriers (i.e., electrons and holes). In turn, this process not only promotes charge separation but also suppresses adverse charge recombination and photocorrosion. ${ }^{18,19}$

While the integration of CCs with PCs and PEs is indispensable for achieving excellent efficiencies, the CC materials have been explored much less than the EC materials. The straightforward application of previously-reported ECs materials as CCs is challenging because it introduces various factors that must each be critically considered. ${ }^{18}$ First, CCs should be small or thin enough so that they do not limit the amount of light absorbed by the $\mathrm{PC}$ and $\mathrm{PE}^{\mathbf{2 0}}$ Second, the change in potential shift at the $\mathrm{CC} /$ semiconductor junction is critical for evaluating charge transfer efficiency. ${ }^{21}$ These additional requirements have not yet been sufficiently addressed, delaying advancement related to CC materials.

In this perspective, we discuss the recent advances in the design of EC materials and the strategies for constructing CC/ $\mathrm{PC}$ and CC/PE composites, including our group's nanoparticle

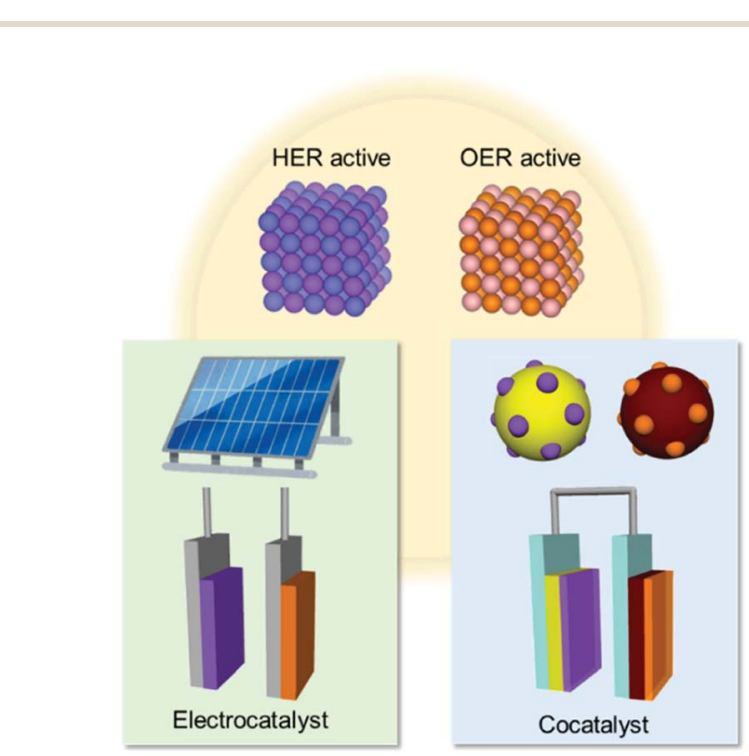

Fig. 1 Application of materials active for solar-driven water splitting via the hydrogen evolution reaction (HER) and oxygen evolution reaction (OER). 
(NP)-adsorption approach. A special emphasis is put on the key principles governing the rational assembly of an efficient CC/PC and CC/PE system. We hope this perspective will inspire researchers in pursuit of bridging the gap between the developments of highly-active EC and CC materials, which have only been studied separately to date (Fig. 1).

\section{Electrocatalysts for water electrolysis}

\subsection{Development of electrocatalyst materials}

Water splitting involves two concurrent catalytic half-reactions: the hydrogen evolution reaction (HER) and the oxygen evolution reaction (OER). Materials that can lower the activation energies of these reactions are utilized as ECs. Although noble metals such as $\mathrm{Pt}, \mathrm{Ru}\left(\mathrm{O}_{x}\right)$ and $\operatorname{Ir}\left(\mathrm{O}_{x}\right)$ are still representative efficient ECs for water splitting, diverse earth-abundant compounds with comparable catalytic activities have also been developed based on comprehensive theoretical and experimental studies. ${ }^{22}$ Herein, we briefly introduce recently-developed EC materials for efficient water splitting and discuss their typical preparation methods. A comprehensive introduction of EC materials is beyond the scope of this perspective; thus, we encourage the interested reader to refer to recent reviews summarizing the development of EC materials. ${ }^{23,24}$

2.1.1 HER electrocatalysts. Platinum $(\mathrm{Pt})$ is a traditional and benchmark HER EC. Theoretically, the binding energy of an $\mathrm{H}$ atom on the EC surface in an intermediate state (defined as $\left.\Delta G_{\mathrm{H}^{*}}\right)$ is widely accepted as an index in the selection of an EC for HER. ${ }^{22}$ It is believed that ECs with $\Delta G_{\mathrm{H}^{*}}=0$ are most suitable for efficient HER, and Pt has the $\Delta G_{\mathrm{H}^{*}}$ closest to 0 among all elements. ${ }^{25}$ From this perspective, materials based on the combination of other elements can be a promising replacement for Pt (a precious metal) if their $\Delta G_{\mathrm{H}^{*}}$ is close to $0 .{ }^{22}$ Significant research efforts have uncovered new combinations of earthabundant elements that exhibit good HER activities (Fig. 2a). ${ }^{23}$ $\mathrm{MoS}_{2}$ was a pioneering EC material ${ }^{26}$ that launched successive explorations into HER-active 2D metal dichalcogenides. With support from theoretical studies, considerable enhancements of the HER activities of $\mathrm{MoS}_{2}$ compounds have been demonstrated by introducing defects and elemental dopants (Fig. 2b)..$^{27,28}$ Metal (Ni, Co, Fe, W, Mo, ...) phosphides, nitrides, and carbides are also subjects of extensive studies owing to their advantageous electronic structures. ${ }^{27,29-38}$ Tuning the metal composition has proven to be pivotal in realizing exceptional HER performance. ${ }^{29}$ Such rationally designed EC compounds have realized comparable HER activities over a wide range of $\mathrm{pH}$ for practical applications.

2.1.2 OER electrocatalysts. Although noble metal-based $\mathrm{IrO}_{x}$ and $\mathrm{RuO}_{x}$ materials remain as the state-of-the-art ECs for OER, ${ }^{39,40}$ earth-abundant $3 \mathrm{~d}$ transition metal-based materials have attracted attention owing to their excellent OER activities (i.e., NiFeOOH). ${ }^{41,42}$ Computational and experimental evidence have shown that the difference between the adsorption energies of the $\mathrm{O}^{*}$ and $\mathrm{OH}^{*}$ intermediates (i.e., $\Delta G_{\mathrm{O}^{*}}-\Delta G_{\mathrm{OH}^{*}}$ ) is a reliable indicator for predicting the OER activity of an EC (Fig. 2c). ${ }^{43}$
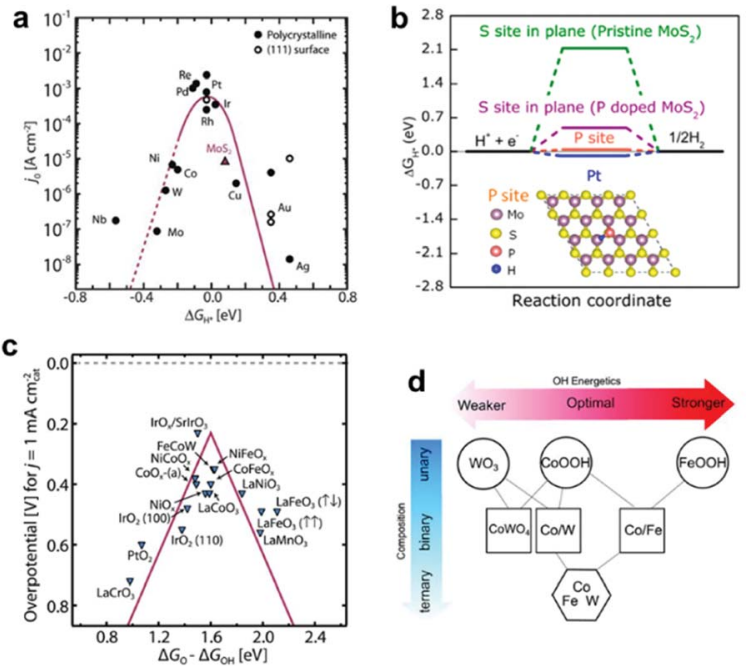

Fig. 2 (a) Volcano plot relating the ECs' HER activities and $\Delta G_{H^{*} ;}$ (b) $\mathrm{HER}$ free-energy diagram for $\mathrm{P}$ and $\mathrm{S}$ sites in the basal plane of pristine and P-doped $\mathrm{MoS}_{2}$; (c) OER volcano plot for metal oxides; (d) $\mathrm{OH}$ adsorption energetics $\left(\Delta G_{\mathrm{OH}^{*}}\right)$ as a function of the material's composition obtained by interpolation between the calculated pure phases of $\mathrm{WO}_{3}$ (001), $\mathrm{CoOOH}(01-12), \mathrm{FeOOH}(010)$, and $\mathrm{CoWO}_{4}$ (010) planes. Adapted with permission from (a and c) ref. 22, (b) ref. 27, and (d) ref. 44; copyright 2017 American Association for the Advancement of Science (AAAS), 2017 the American Chemical Society (ACS), and 2016 AAAS, respectively.

For example, Sargent et al. used theory and experiments to establish that an exceptional OER activity can be attained by tailoring the material's composition in terms of three metals ( $\mathrm{Co}, \mathrm{Fe}$, and $\mathrm{W}$ ), which enables an optimization of $\Delta G_{\mathrm{OH}^{*}}$ (Fig. 2d). ${ }^{44}$ In addition, researchers have discovered that chalcogenides and phosphides containing two or more types of metals can also function as excellent OER ECs. ${ }^{44-54}$

2.1.3 Bifunctional compounds as electrocatalysts. While exploring new EC materials, researchers have identified various compounds that are highly-active for both HER and OER. For example, multi-metallic compounds, such as oxides, phosphides, and chalcogenides, achieve efficient overall water splitting in a two-electrode configuration driven by a cell voltage of $\sim 1.6 \mathrm{~V}$ in alkaline electrolyte (Table 1). ${ }^{48,55-60}$ Higher $\mathrm{pH}$ conditions (alkaline media) are usually more appropriate for such bifunctional materials because they facilitate the ratedetermining OER, which has a larger overpotential than the HER. ${ }^{61}$ Bifunctional EC materials represent promising CCs for photocatalytic water splitting owing to their inherent abilities to promote HER and OER simultaneously.

\subsection{Synthesis and use of electrocatalysts}

To date, innovative EC materials have been synthesized through various chemical and physical routes. Because the overall size of the ECs does not require fine-tuning (as long as they are conductive enough to work on electrodes), they have mainly been fabricated using facile strategies, including solvothermal syntheses, solid-state reactions, and electrochemical deposition (Fig. 3a). This enables rapid and widespread exploration of 
Table 1 Selected recently-developed multi-metallic EC materials and their performance compared with conventional EC ${ }^{a}$

\begin{tabular}{|c|c|c|c|c|c|}
\hline EC & Preparation method & Catalysis & $\begin{array}{l}\text { Overpotential } \\
\left(\mathrm{mV} \text { for } 10 \mathrm{~mA} \mathrm{~cm}^{-2}\right)\end{array}$ & Electrolyte & Ref. \\
\hline P-doped $\mathrm{MoS}_{2}$ & Hydrothermal & HER & 43 & $0.5 \mathrm{M} \mathrm{H}_{2} \mathrm{SO}_{4}$ & 27 \\
\hline $\mathrm{Re}_{1-x} \mathrm{Mo}_{x} \mathrm{Se}_{2}$ & Hydrothermal & HER & 77 & $0.5 \mathrm{M} \mathrm{H}_{2} \mathrm{SO}_{4}$ & 34 \\
\hline $\mathrm{Fe}_{0.5} \mathrm{Co}_{0.5} \mathrm{P}$ & Hydrothermal + phosphidation & HER & 37 & $0.5 \mathrm{M} \mathrm{H}_{2} \mathrm{SO}_{4}$ & 33 \\
\hline $20 \mathrm{w} \% \mathrm{Pt} / \mathrm{C}$ & Commercial & HER & 27 & $0.5 \mathrm{M} \mathrm{H}_{2} \mathrm{SO}_{4}$ & 34 \\
\hline $\mathrm{Fe}_{3} \mathrm{GeTe}_{2}$ & Solid-state reaction & HER & 105 & $1 \mathrm{M} \mathrm{KOH}$ & 35 \\
\hline $\mathrm{Ni}_{2} \mathrm{Mo}_{3} \mathrm{~N}$ & Nitridation & HER & 21.3 & $1 \mathrm{M} \mathrm{KOH}$ & 36 \\
\hline $\mathrm{Ni}_{6} \mathrm{Mo}_{6} \mathrm{C} / \mathrm{NiMoO}_{x}$ & Hydrothermal + carburization & HER & 29 & $1 \mathrm{M} \mathrm{KOH}$ & 37 \\
\hline $20 \mathrm{w} \% \mathrm{Pt} / \mathrm{C}$ & Commercial & HER & 32 & $1 \mathrm{M} \mathrm{KOH}$ & 37 \\
\hline G-FeCoW & Sol-gel & OER & 191 & $1 \mathrm{M} \mathrm{KOH}$ & 44 \\
\hline NiCoFe-P-NP@NiCoFe-PBA & Precipitation + phosphidation & OER & 223 & $1 \mathrm{M} \mathrm{KOH}$ & 49 \\
\hline$(\mathrm{CrMnFeCoNi}) \mathrm{S}_{x}$ & Pulse thermal decomposition & OER & 116 & $1 \mathrm{M} \mathrm{KOH}$ & 51 \\
\hline CoVFeN & Hydrothermal + electrodeposition + nitridation & OER & 212 & $1 \mathrm{M} \mathrm{KOH}$ & 53 \\
\hline $\mathrm{Mo}_{6} \mathrm{Ni}_{6} \mathrm{C}$ & Hydrothermal + carburization & OER & 190 & $1 \mathrm{M} \mathrm{KOH}$ & 54 \\
\hline $\mathrm{RuO}_{2}$ & Commercial & OER & 264 & $1 \mathrm{M} \mathrm{KOH}$ & 49 \\
\hline $\mathrm{IrO}_{2}$ & Commercial & OER & 290 & $1 \mathrm{M} \mathrm{KOH}$ & 54 \\
\hline NiFe LDH & Electrodeposition & OER & $250-300$ & $1 \mathrm{M} \mathrm{KOH}$ & 52 \\
\hline RuIr & Chemical reduction & OWS & 255 & $0.05 \mathrm{M} \mathrm{H}_{2} \mathrm{SO}_{4}$ & 56 \\
\hline $\mathrm{SrNb}_{0.1} \mathrm{Co}_{0.7} \mathrm{Fe}_{0.2} \mathrm{O}_{3-\delta}$ & Solid-state reaction & OWS & 450 & $1 \mathrm{M} \mathrm{KOH}$ & 55 \\
\hline $\mathrm{MoS}_{2} / \mathrm{Ni}_{3} \mathrm{~S}_{2}$ & Solvothermal & OWS & 330 & $1 \mathrm{M} \mathrm{KOH}$ & 57 \\
\hline NiMoP NSs@MCNTs & Hydrothermal & OWS & 369 & $1 \mathrm{M} \mathrm{KOH}$ & 58 \\
\hline $\mathrm{Ni}-\mathrm{Fe}-\mathrm{MoN}$ & Solid-state reaction & OWS & 228 & $1 \mathrm{M} \mathrm{KOH}$ & 59 \\
\hline
\end{tabular}

novel EC materials via screening experiments. ${ }^{62}$ Simple oxides and chalcogenides can be directly synthesized by liquid-phase methods under mild conditions, ${ }^{62,63}$ whereas hightemperature annealing is often required to obtain phosphides, nitrides, and carbides from their corresponding preformed oxides. ${ }^{34-36,51,52}$ Specifically, they are annealed with precursors ( $\mathrm{P}=\mathrm{NaH}_{2} \mathrm{PO}_{2} ; \mathrm{N}=\mathrm{NH}_{3} ; \mathrm{C}=$ organic molecule) in a furnace at $>300{ }^{\circ} \mathrm{C}$ for complete conversion. To assess the resulting material's electrocatalytic activity, powdered ECs are embedded on a conductive carbon substrate, and the composite
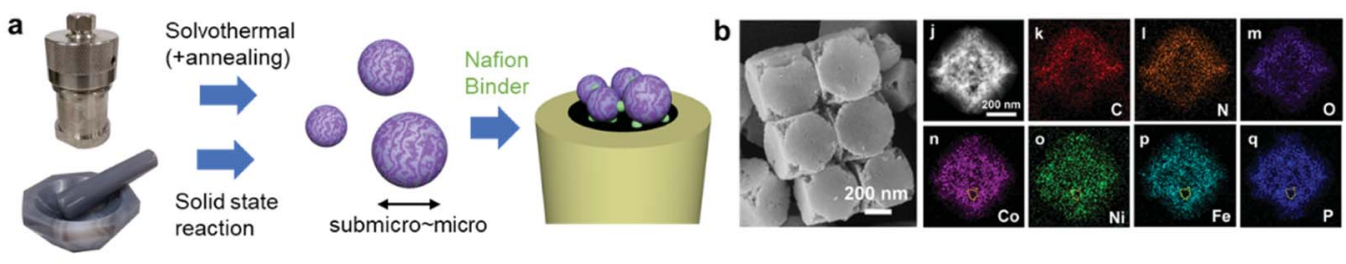

c

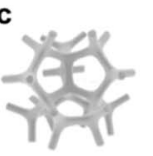

Ni Foam

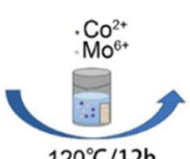

$120^{\circ} \mathrm{C} / 12 \mathrm{~h}$

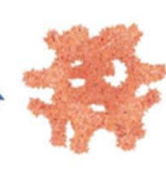

$\mathrm{Ni}$ Foam/CoMoO ${ }_{4} \times \mathrm{H}_{2} \mathrm{O}$

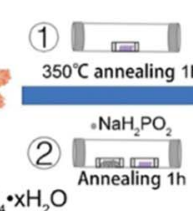

$\mathrm{Ni}$ Foam/P-CoMoO
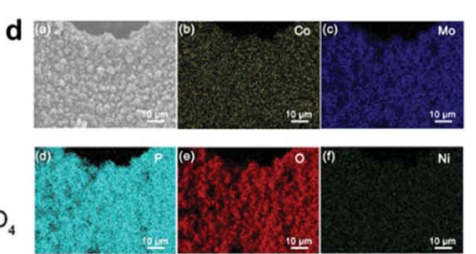
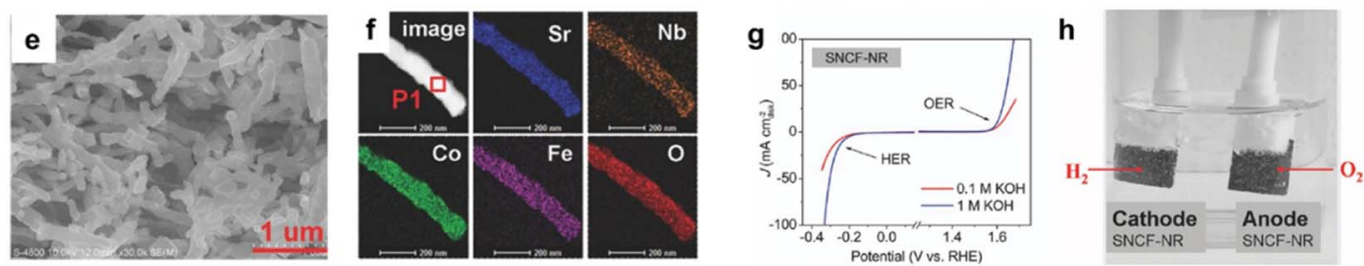

Fig. 3 (a) Typical synthetic strategies for powdered ECs and the corresponding electrode preparation; (b) MOF-derived NiCoFe-P NPs containing porous nanocages; (c) direct $\mathrm{EC}\left(\mathrm{P}-\mathrm{CoMoO}_{4}\right)$ growth on a Ni foam electrode through a solvothermal method and phosphidation via annealing; (d) elemental mapping of a $\mathrm{Ni}$ foam $/ \mathrm{P}-\mathrm{COMOO}_{4}$ composite electrode; (e) scanning electron microscopy (SEM) and (f) elemental mapping images, (g) CV, and (h) overall water-splitting experiment using a bifunctional $\mathrm{SrNb}_{0.1} \mathrm{CO}_{0.7} \mathrm{Fe}_{0.2} \mathrm{O}_{3-\delta}$ EC. Adapted with permission from (b) ref. 49, (c and d) ref. 38, and (e-h) ref. 55; copyright 2021 ACS, 2020 Wiley, and 2017 Wiley, respectively. 
is typically glued to an electrode surface using a Nafion binder. ${ }^{\mathbf{6 4}}$ ECs can also be grown directly on porous conductive supports, such as metal foam or carbon paper/cloth, which increase their conductivity and loading per geometrical unit area (Fig. 3c and d). ${ }^{37,38,65}$ Such EC-grown substrates can be directly connected to a potentiostat as free-standing electrodes. Alternatively, nanosizing is a practical approach for designing active ECs with large surface areas because it provides unsaturated surface atoms and promotes greater atomic usage efficiency. ${ }^{23}$ Effective techniques for fabricating EC nanoparticles (NPs) include colloidal synthesis and precursor decomposition on a support material. ${ }^{51,66}$ Annealing a metal-organic framework (MOF) is a facile technique to produce multi-metallic NPs supported on a porous conductive carbonaceous substrate (Fig. 3b). ${ }^{49}$ Moreover, recent advances have revealed that single-atom (SA) catalysts are emerging as new ECs with exceptional properties, such as maximum atomic usage efficiency, high activity of the metal complex, and high durability of the bulk catalyst. ${ }^{67}$ Similar to powdered ECs, EC NPs and SA catalysts can be supported on conductive substrates and fixed to an electrode. These EC electrodes operate as working electrodes in a three (working, reference, and counter)-electrode system to evaluate their catalytic performance towards HER and/or OER ${ }^{68}$ Overall water splitting is investigated in a two (working + counter)-electrode configuration using two identical EC-immobilized electrodes (Fig. 3h). ${ }^{55}$

It is worth noting that ECs can undergo some changes during catalysis, especially in a OER environment. ${ }^{69}$ According to the Pourbaix diagram, the surface or entire EC can transform into its corresponding [(oxy)hydr]oxide under alkaline
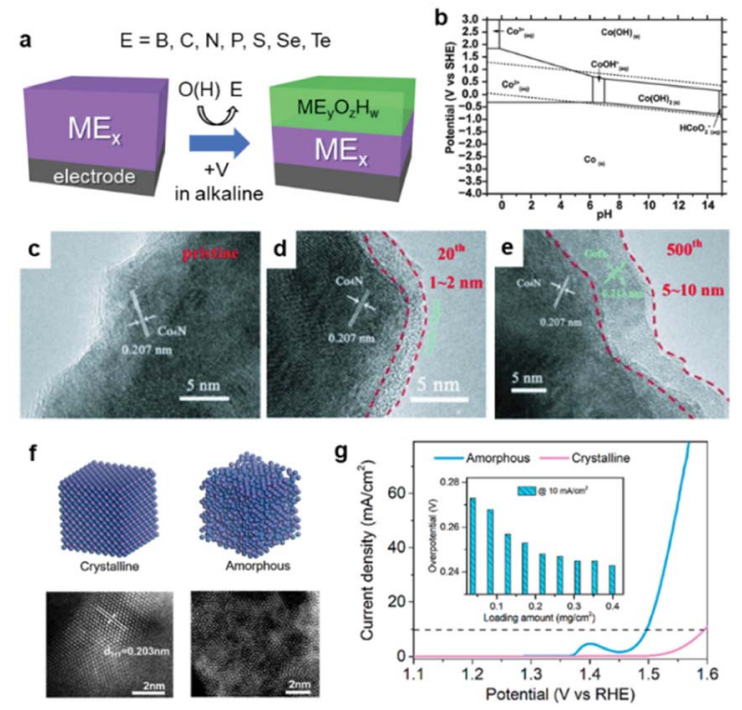

Fig. 4 (a) Schematic diagram illustrating the in situ oxidation of an EC; (b) Pourbaix diagram of $\mathrm{Co}-\mathrm{H}_{2} \mathrm{O}$ system; (c-e) transmission electron microscope (TEM) images of the $\mathrm{CO}_{4} \mathrm{~N}$ EC surface before and after 20 and 500 cycles of CV for OER; (f) structural differences between crystalline and amorphous NiFe and (g) their corresponding OER polarization curves. Adapted with permission from (b) ref. 70, (c-e) ref. 71, and (f and g) ref. 72; copyright 2019 the Royal Society of Chemistry (RSC), 2015 Wiley, and 2020 ACS, respectively. conditions under a positive applied potential (Fig. $4 \mathrm{a}-\mathrm{e}) \cdot{ }^{70} \mathrm{Wu}$ et al. reported that the surface of $\mathrm{Co}_{4} \mathrm{~N}$ was progressively oxidized during OER cyclic voltammetry (CV) experiments in $1 \mathrm{M} \mathrm{KOH}$ electrolyte. ${ }^{71}$ Even if the composition is carefully controlled during synthesis, the real active species may deviate from the as-prepared material. Such transformed oxides and (oxy)hydroxides frequently exhibit superior catalytic activities because their amorphous surfaces offer more active sites and enhanced electronic interactions relative to their pure oxide analogs (Fig. $4 \mathrm{f}$ and $\mathrm{g}$ ). ${ }^{72}$ In calculations of the surface state, a lack of understanding of the real active species may mislead research conclusions.

\section{Cocatalysts for PC and PEC systems}

In the case of solar cell-assisted water splitting, EC-loaded electrodes can be employed in the same configuration as two electrode system. Therefore, improving intrinsic catalytic activity of EC directly increases the STH, aside from the solar cell efficiency. In terms of PC and PEC systems, the latest advancements in semiconductor design (e.g., defect engineering and morphology control) have paved the way for advanced PCs and PEs with high light-energy conversion efficiencies. ${ }^{73}$ Nevertheless, additional considerations concerning the successful integration of efficient EC materials as CCs onto the PC and PEC systems must be addressed. First, it is essential for the CCs to have suitable NP dimensions and homogenous distribution on the PC and PE to ensure that they do not block the incident light. Second, designing an optimal interface between the semiconductor and CC is necessary because the stability and performance of the entire system largely depend on this junction. Such requirements significantly limit the range of material dimensions (e.g. size, shape, and light absorbance.) that can be viewed as valuable for CCs, thereby hindering further development of CC research compared with EC research.

Despite these difficulties, a significant amount of effort has been dedicated to the hybridization of water-splitting catalyst materials with semiconductors to realize high-performance photocatalytic and PEC systems. ${ }^{74}$ Unlike in the synthesis of ECs, the stability of PCs and PEs must be considered when constructing CC/semiconductor composites. PCs based on (oxy) nitride and (oxy)chalcogenide decompose easier than pure oxides, while other PCs become inactive because of a change in the metal valence. ${ }^{75}$ As introduced in Section 2, some methods for efficient EC formation require high-temperature annealing, and such a harsh condition cannot be applied to unstable semiconductors. In this section, we summarize representative strategies for loading CCs onto PCs and PEs (Fig. 5a, Tables 2 and 3 ).

\subsection{Cocatalysts loading on powdery photocatalysts}

In photocatalysis using powdery PCs, both reduction and oxidation reactions take place on an individual PC particle, requiring two suitable surfaces on an PC particle to drive each 
a

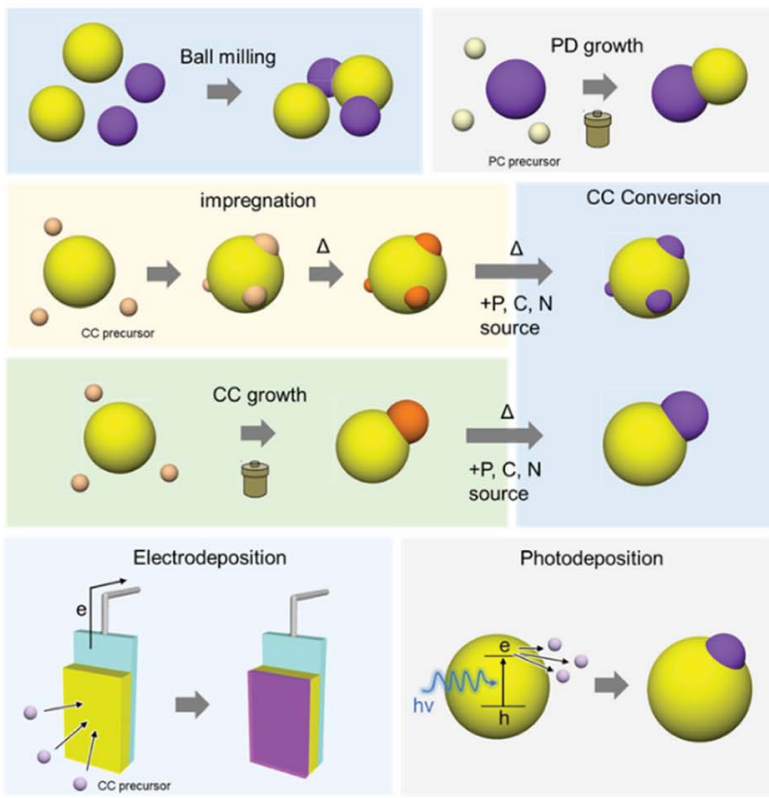

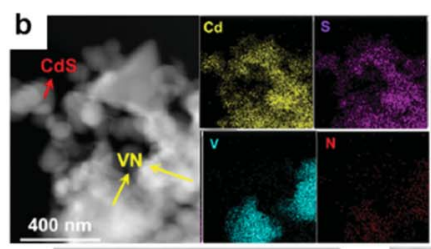
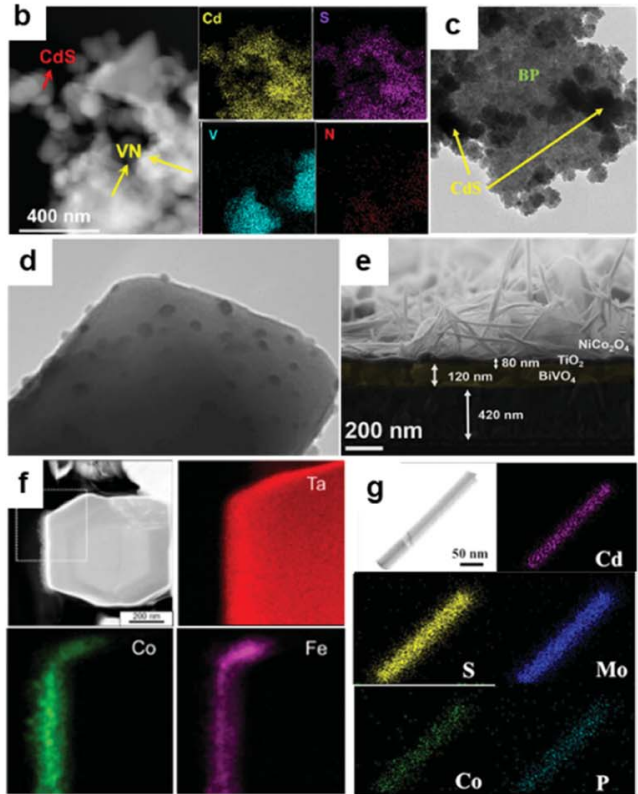

Fig. 5 (a) Representative strategies for assembling CC/PC composites; (b) VN loaded on CdS via ball-milling; (c) CdS grown on BP via a hydrothermal method; (d) $\mathrm{Ca}_{2} \mathrm{FeCOO}_{5}$ loaded on $\mathrm{TiO}_{2}$ via impregnation; (e) $\mathrm{NiCO}_{2} \mathrm{O}_{4}$ grown on a $\mathrm{TiO}_{2} / \mathrm{BiVO}_{4}$ photoelectrode via a hydrothermal method; (f) $\mathrm{CoO}_{x}-\mathrm{FeO}_{x}$ coated on $\mathrm{Ta}_{3} \mathrm{~N}_{5}: \mathrm{Mg}+\mathrm{Zr}$ via electrodeposition; (g) $\mathrm{MoS}_{2}$ and CoPi loaded on CdS nanowires via photodeposition. Adapted with permission from (b) ref. 80, (c) ref. 87, (d) ref. 101, (e) ref. 127, (f) ref. 134, and (e) ref. 122; copyright 2019 ACS, 2020 ACS, 2020 Wiley, 2020 ACS, 2015 ACS, and 2019 ACS, respectively.

particular half-reaction. Generally, CCs for a specific halfreaction are first loaded onto the PC surface leaving the other regions available to facilitate the other half-reaction, which is especially advantageous for examining individual half-reactions including the cases using sacrificial reagents. For overall watersplitting PC, the loading of CCs for both HER and OER can further accelerate the total reaction to attain higher photocatalytic performance. ${ }^{76}$
3.1.1 Hybridizing photocatalysts with cocatalysts. Mechanical mixing is the simplest way to modify a PC with an CC. Ultrasonication and (ball-)milling (a physical mixing method) are useful for preparing a well-mixed powdery composite. ${ }^{77-82}$ Thermal treatment application is often necessary to strengthen the interfacial contact after mixing. ${ }^{83-86}$ The main advantage of this technique is that it does not impose any restrictions on the type of PC or CC that can be used; thus,

Table 2 AQY of powdery CdS PC/CC prepared by various hybridization methods

\begin{tabular}{|c|c|c|c|c|}
\hline CC & Loading method & $\begin{array}{l}\text { AQY (\% } \\
\text { (a) } 420 \mathrm{~nm})\end{array}$ & Sacrificial reagent & Ref. \\
\hline $\mathrm{VN}$ & Sonication & 5.3 & Lactic acid & 80 \\
\hline WP & Ball-milling & 10.5 & $\left(\mathrm{NH}_{4}\right)_{2} \mathrm{SO}_{3}$ & 82 \\
\hline $\mathrm{Co}_{3} \mathrm{C}$ & Mixing + annealing & 17 & $\mathrm{Na}_{2} \mathrm{SO}_{3}+\mathrm{Na}_{2} \mathrm{~S}$ & 86 \\
\hline FeSe & Sonication + annealing & 6.71 & $\mathrm{Na}_{2} \mathrm{~S}+\mathrm{Na}_{2} \mathrm{SO}_{3}$ & 85 \\
\hline $\mathrm{Ni}_{3} \mathrm{~S}_{2}$ & PC growth & 7.86 & Lactic acid & 93 \\
\hline $\mathrm{Mo}_{2} \mathrm{~N}$ & PC growth & 2.2 & $\mathrm{Na}_{2} \mathrm{~S}+\mathrm{Na}_{2} \mathrm{SO}_{3}$ & 94 \\
\hline $\mathrm{WS}_{2}$ & Impregnation & 5.0 & Lactic acid & 98 \\
\hline $\mathrm{CoO}$ & Impregnation & 40.64 & Lactic acid & 99 \\
\hline $\mathrm{NiS}$ & Hydrothermal & 74.1 & Lactic acid & 106 \\
\hline $\mathrm{MoS}_{2}$ & Hydrothermal & 41.37 & Lactic acid & 107 \\
\hline $\mathrm{CoPi}$ & Photodeposition & 24.3 & Lactic acid & 121 \\
\hline $\mathrm{MoS}_{2}-\mathrm{CoPi}$ & Photodeposition & 36 & Lactic acid & 122 \\
\hline
\end{tabular}


Table 3 Examples of anodic PEs loaded with CC in various methods

\begin{tabular}{|c|c|c|c|c|}
\hline Semiconductor & $\mathrm{CC}$ & CC loading method & $\begin{array}{l}\text { Photocurrent density } \\
\left(\mathrm{mA} \mathrm{cm} \text { cm }^{-2} \text { @ } 1.23 \mathrm{~V}\right)\end{array}$ & Ref. \\
\hline $\mathrm{BiVO}_{4}$ & FeSnOS & Impregnation & 3.1 & 124 \\
\hline $\mathrm{BiVO}_{4} / \mathrm{TiO}_{2}$ & $\mathrm{NiCo}_{2} \mathrm{O}_{4}$ & Hydrothermal & 2.47 & 127 \\
\hline $\mathrm{BiVO}_{4}$ & NiFeY LDH & Hydrothermal & 5.2 & 128 \\
\hline $\mathrm{BiVO}_{4}$ & $\mathrm{~F}: \mathrm{Co}\left(\mathrm{CO}_{3}\right)_{x} \mathrm{OH}_{y}$ & Hydrothermal & 5.5 & 129 \\
\hline $\mathrm{BiVO}_{4}$ & $\mathrm{Co}-\mathrm{LaFeO}_{3}$ & Electrodeposition & 3.4 & 135 \\
\hline $\mathrm{BiVO}_{4}$ & $\mathrm{FeOOH} / \mathrm{NiOOH}$ & Light-assisted electrodeposition & 4.2 & 136 \\
\hline $\mathrm{BiVO}_{4}$ & $\mathrm{NiP}_{x} @ \mathrm{FeP}_{y} \mathrm{O}_{z}$ & NP adsorption & 2.3 & 148 \\
\hline $\mathrm{BiVO}_{4}$ & $\mathrm{CuCoO}_{2}$ & NP adsorption + annealing & 3.32 & 126 \\
\hline $\mathrm{Ta}_{3} \mathrm{~N}_{5}$ & $\mathrm{FeNiO}_{x}$ & Impregnation & 9.95 & 125 \\
\hline $\mathrm{Ta}_{3} \mathrm{~N}_{5}$ & FeNiCo & Electrodeposition & 4.0 & 133 \\
\hline $\mathrm{Ta}_{3} \mathrm{~N}_{5}$ & $\mathrm{Co}-\mathrm{Pi} / \mathrm{Co}(\mathrm{OH})_{x} / \mathrm{NiFe}-\mathrm{LDH}$ & Adsorption + electrodeposition + solvothermal & 6.3 & 137 \\
\hline $\mathrm{Ta}_{3} \mathrm{~N}_{5}$ & $\mathrm{Ni}: \mathrm{CoFeO}_{x}$ & Light-assisted electrodeposition & 5.3 & 138 \\
\hline
\end{tabular}

a wide range of metal alloys, phosphides, nitrides, borides, carbides, and chalcogenides can be employed. For example, simple ball-milling can yield a CdS/VN composite without decomposing either constituent (Fig. 5b). ${ }^{\mathbf{8 0}}$

Chemical methods are also applicable to hybridize PC with synthetic CC materials. Adding a CC to a PC synthetic system can grow typical PCs, such as CdS, on the CC surface under mild hydrothermal conditions (Fig. 5c). ${ }^{87-94}$ However, this technique is not viable for bulk oxide-based PCs (e.g., $\left.\mathrm{SrTiO}_{3}\right)$ which require high-temperature $\left(>800{ }^{\circ} \mathrm{C}\right)$ solid-state synthetic reactions that can lead to CC decomposition.

3.1.2 Cocatalyst growth and transformation on photocatalysts. A simple route to deposit a nanoparticulate metal oxide CC on a PC is through an impregnation method. ${ }^{95-99}$ Typically, the CC precursor solution and the PC are successively mixed and dried, followed by an annealing step to completely convert the precursors into active CC components. This strategy also enables homogeneous confinement of certain elements in small domains, thus allowing for facile manipulation of the metal composition. Although the majority of reported examples only describe a single type of metal, the deposition of multimetallic oxide CCs has also been achieved. For example, $\mathrm{RhCrO}_{x}$ (a popular CC for photocatalytic water splitting) is commonly fabricated using this process. ${ }^{\mathbf{1 0 0}}$ Tsuji et al. also performed a simple impregnation to load ternary-metallic Brownmillerite $\mathrm{Ca}_{2} \mathrm{FeCoO}_{5} \mathrm{NPs}$ onto a $\mathrm{TiO}_{2} \mathrm{PC}$ (Fig. 5d). ${ }^{\mathbf{1 0 1}}$ However, this route requires high-temperature annealing to decompose the precursor salts, and this limits its application for thermally-unstable PCs. Moreover, fine-tuning of the CC size is difficult, and aggregation may adversely affect the catalytic performance of the CC. ${ }^{\mathbf{1 0 2}}$ A solvothermal method can also be applied to grow metal (hydr)oxide or sulphide CCs directly on a PC. ${ }^{\text {103-107 }}$ The straightforward addition of the PC into the EC synthesis solution can generate a CC/PC composite.

As mentioned in Section 2, a gas phase reaction can be employed to modify the composition of preformed oxide CCs. To promote the formation of high-quality chalcogenide, phosphide, nitride, and carbide CCs, which hardly form via impregnation or solvothermal methods, supplemental annealing treatments must be implemented. As a result, stable PCs with excellent thermal resistance $\left(e . g ., \mathrm{C}_{3} \mathrm{~N}_{4}\right)$ are mostly used for this approach. ${ }^{\mathbf{1 0 8 - 1 1 1}}$

3.1.3 Photodeposition. Irradiating the PC with light is a clever way to create an internal potential through the excitation of carriers, which can reduce or oxidize the precursor to form nanoparticulate CCs. ${ }^{\mathbf{1 1 2}}$ Because photodeposition occurs at sites where photogenerated carriers preferentially migrate, CCs tend to nucleate on specific crystal planes of a PC, thus enabling location-controlled CC deposition. ${ }^{\mathbf{1 4}}$ Photodeposition can also be performed at RT, and therefore, unstable materials [e.g., (oxy)nitrides and (oxy)sulphides] can be used as the PC. ${ }^{113,114}$ Researchers have demonstrated that metal or metal oxide CCs, such as Rh, Pt, $\mathrm{MnO}_{x}$, and $\mathrm{CoO}_{x}$ can be loaded using this strategy. ${ }^{\mathbf{1 1 5 , 1 1 6}}$ Recently, S- or P-containing precursors have been used for photodepositing metal sulphides and phosphates, respectively. ${ }^{117-121} \mathrm{Xu}$ et al. photodeposited $\mathrm{MoS}_{x}$ and cobalt phosphate (CoPi) CCs on $\mathrm{CdS}$ nanowires using $\left(\mathrm{NH}_{4}\right)_{2} \mathrm{MoS}_{4}$ and $\left[\mathrm{Co}\left(\mathrm{NO}_{3}\right)_{2}+\mathrm{Na}_{3} \mathrm{PO}_{4}\right]$, respectively (Fig. 5g), ${ }^{122}$ thereby validating the possibility of depositing complicated multi-metallic CCs on a PC under mild conditions.

In order to shed some light on the dependence of photocatalytic performance on the type of CC-loading method, apparent quantum yield (AQY) values (at $420 \mathrm{~nm}$ ) for wellstudied CdS/CC composites in the presence of hole scavengers are listed in Table 2. Although fair comparison between works under different conditions is difficult, rough tendency of AQY depending on loading method can be seen. CdS PCs loaded with CCs through physical mixing tend to show relatively lower AQY of around 10\%. Meanwhile, CdS/CC composites assembled using hydrothermal and photodeposition methods can reach much higher AQY of up to $\sim 70 \%$. These results suggest that the creation of an atomic-level PC/CC interface is paramount for a smooth carrier migration and reduced bulk recombination of photogenerated charge carriers in PCs.

\subsection{Cocatalysts loading on photoelectrodes}

In PEC systems, the photogenerated minority carriers diffuse to the semiconductor surface and the majority carriers are collected by the conductive substrate. For example, in photoanode containing n-type semiconductor, the electrons travel to 
the counter electrode, and the holes on photoanode surface and the electrons on the counter electrode surface are used to drive oxidation and reduction half-reactions, respectively. Therefore, unlike powdery PC systems, only one half-reaction (oxidation on n-type and reduction on p-type semiconductor) takes place on the PE surface, which requires the loading of appropriate CCs for each reaction.

Accordingly, efficient collection of majority carriers (holes in p-type and electrons in n-type semiconductors) requires a small resistance at the semiconductor/electrode interface and within the grain boundaries of semiconductor layer. ${ }^{123}$ Hence, CCs are typically loaded after fabricating high-quality PEs, wherein a mild CC-loading condition is necessary not to damage those prebuilt PEs. Impregnation by drop casting the CC precursor and a subsequent mild annealing is often applied when constructing CC/PE composites. ${ }^{\text {124-126 }}$ Hydrothermal method can also be employed by immersing PEs in a reaction vessel containing CC precursors (Fig. 5e). ${ }^{\mathbf{1 2 7 - 1 2 9}}$ These methods enable the formation of multi-metallic oxide CC layer on relatively unstable semiconductors like $\mathrm{Ta}_{3} \mathrm{~N}_{5}$ (Table 3 ). ${ }^{\mathbf{1 3 0}}$

An effective technique to homogeneously coat a CC layer on PEs is an electrodeposition. By applying a potential using a potentiostat, CCs can be deposited as reduced or oxidized species on the PE surface. Light-irradiation is sometimes applied during electrodeposition to assist adequate CC-loading under small applied potential. A representative example of an electrodeposited CC is a CoPi thin film, which is formed by oxidizing a Co precursor with a phosphate electrolyte. ${ }^{\mathbf{1 3 1}}$ In addition, $\mathrm{FeOOH}, \mathrm{NiOOH}$, and $\mathrm{CoOOH}$ are popular OER CCs that can be anodically deposited in a similar way. ${ }^{\mathbf{1 3 2 - 1 3 8}}$ These catalysts, coated as homogeneous thin films or NPs, have low absorption coefficients, which is a desirable feature for a CC. Considering that electrodeposition can be carried out at room temperature (RT), both robust $\mathrm{BiVO}_{4}$ and fragile $\mathrm{Ta}_{3} \mathrm{~N}_{5}$ PCs can be used in this method (Fig. 5f).

\subsection{Nanoparticle-adsorption approach}

Recent milestones in colloidal synthesis allow for the preparation of advanced NPs with controlled size and composition. ${ }^{139}$ Colloidal NPs represent ideal CC candidates because they can offer numerous active sites and enable uninterrupted light absorption by the semiconductor. Selective binding of organic ligands on the NP surface grants the opportunity to precisely engineer their surface. ${ }^{\mathbf{1 4 0}}$ Specifically, organic molecules, which have polar functional groups at both ends, can link the NP and semiconductor through hydrogen bonding between the functional groups and $\mathrm{OH}$ units on the PC surface (Fig. 7a). However, such ligands behave as an insulating, carrier-blocking layer at the CC/semiconductor interface, and therefore, they should be eliminated (Fig. 6). The standard approach to remove these protective ligands and activate the NP catalysts involves applying an annealing treatment. Previous reports have shown that the required annealing temperature for complete ligand removal changes depending on the type of ligand and the PC support. Our group successfully deposited monodisperse Rh NPs as HER
CCs on a GaN:ZnO PC. ${ }^{\mathbf{1 4 1 - 1 4 5}}$ Specifically, ultrasmall polyvinylpyrrolidone (PVP) coated-Rh NPs were first adsorbed onto the PC using a linker molecule and then annealed in air at $400{ }^{\circ} \mathrm{C}$ (Fig. 7a). Interestingly, the size of the NPs remained $\sim 1 \mathrm{~nm}$ without aggregation after annealing. Negishi et al. also verified the crucial role of annealing to eliminate the ligands on $\mathrm{Au}$ clusters without changing their size. ${ }^{\mathbf{1 4 6}}$ Such ultrafine NP deposition can only be realized through an NP-adsorption strategy. Depositing ultrasmall CCs can drastically enhance the photocatalytic performance of the composite because the NPs introduce a larger surface area and a greater number of active sites. ${ }^{141}$ However, larger NPs could reduce the number of cocatalytic sites at the same degree of loading, and this might shield the incident light needed for carrier generation. In this context, fine-tuning the NPs can contribute to a deeper fundamental understanding of the $\mathrm{CC}$ effect (e.g., size and structure effects) on photocatalysis (Fig. 7b). ${ }^{\mathbf{1 4 4}}$

Although a thermal treatment is favourable for ligand removal, elevated temperatures and a harsh environment may cause irreversible damage to the PC, PE and the CC NPs. Alternatively, replacing long-chain ligands with small surface-coordinating molecules is an effective way to increase the interfacial contact between the NPs and semiconductor under mild conditions. For example, our group treated oleylamine (OAm)-capped $\mathrm{Ni}_{3} \mathrm{~S}_{4} \mathrm{NPs}$ with $\mathrm{S}^{2-}$ at RT to replace the OAm and yield $\mathrm{S}^{2-}$-stabilized $\mathrm{Ni}_{3} \mathrm{~S}_{4}$ NPs (Fig. 7c-e), ${ }^{147}$ which were then directly deposited on a $\mathrm{CdS} / \mathrm{Cu}(\mathrm{In}, \mathrm{Ga}) \mathrm{Se}_{2} \mathrm{PE}$ through a layer-by-layer assembly process. Remarkably, the $\mathrm{PE}$ coated with $\mathrm{S}^{2-}-\mathrm{Ni}_{3} \mathrm{~S}_{4}$ NPs exhibited an increase in cathodic photocurrent compared with the OAm-Ni $\mathrm{S}_{4}-\mathrm{NPs}$ spin-coated PE, which highlighted the importance of establishing good contact between the CC and PE (Fig. 7f). Additionally, heating treatment to remove OAm from OAm-Ni ${ }_{3} \mathrm{~S}_{4}$ layers at $300{ }^{\circ} \mathrm{C}$ resulted in deterioration of $\mathrm{CdS} / \mathrm{Cu}(\mathrm{In}, \mathrm{Ga}) \mathrm{Se}_{2}$ $\mathrm{PE}$. These results demonstrate that the chemical ligandremoval process can enable the application of NP CCs to unstable PEs.

By exploiting the transformation phenomenon of ECs during catalysis, we demonstrated that applying potential for OER to a NiP ${ }_{x} @ \mathrm{FeP}_{y} \mathrm{O}_{z}$ NP-loaded electrode transformed the NPs into highly OER active NiFeOOH film while simultaneously removing their organic ligands (Fig. 8). ${ }^{\mathbf{1 4 8}}$ Notably, the colour of the NPs changed from black (phosphide) to colourless (hydroxide), with enhanced transparency for incident visible light. Such a characteristic transformation is highly advantageous for coupling NPs with PCs and PEs under mild conditions. Evidently, the $\mathrm{NiP}_{x} @ \mathrm{FeP}_{y} \mathrm{O}_{z} \mathrm{NP}$ deposition substantially increased the photocurrent of the $\mathrm{BiVO}_{4} \mathrm{PE}$ without any posttreatment (Fig. 8c-g), showing that homogeneous NP dispersion can be used as ready-to-use CC ink.

\section{Application of ECs to CCs}

As discussed in Section 3, PCs and PEs can be modified with CCs through a variety of strategies to significantly enhance their water-splitting efficiencies. Potential opportunities to further improve the activity could be foreseen if the factors limiting the 
a
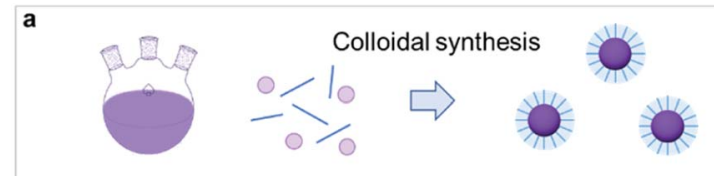

b

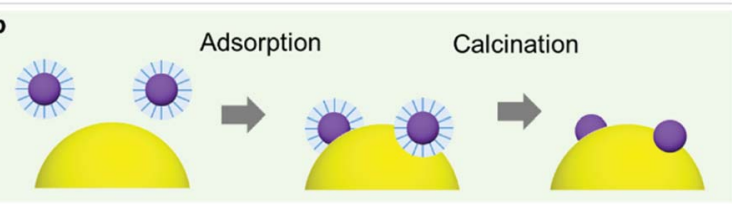

c

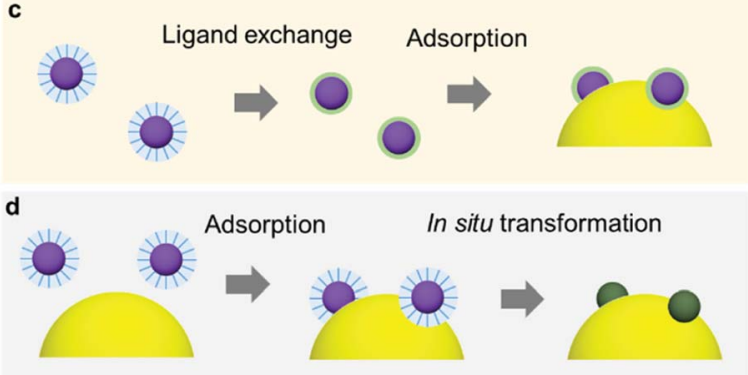

Fig. 6 (a) Colloidal synthesis of monodisperse NPs; (b) NP loading via adsorption and subsequent calcination to remove protective organic ligands; (c) ligand exchange method to replace bulky organic ligands with small inorganic ions; (d) spontaneous ligand removal during catalysis.

activity could be identified. For example, what are the core principles relevant for unlocking high-performance CC/PC and $\mathrm{CC} / \mathrm{PE}$ systems and bypassing rigorous material screening experiments? In this section, we introduce fundamental concepts that play a significant role in designing advanced ECs as CCs for photocatalytic and PEC water splitting.

\subsection{Energy level matching at the $\mathrm{CC} /$ semiconductor interface}

When an EC comes in contact with a semiconductor, the band structure of the semiconductor is modulated. ${ }^{149}$ In general, an electronic contact between a metallic CC and a semiconductor initiates an electron transfer between the semiconductor and the CC until their Fermi levels $\left(E_{\mathrm{F}}\right.$; the energy level with a $50 \%$ probability of electron occupation) equilibrate, which forms a space charge layer. In the space charge layer, the band edge energies of the semiconductor are continuously shifted by the electric field between the semiconductor and the metallic CC. As a result, the energy bands of the semiconductor bend toward the CC. The band bends upward (downward) when the $E_{\mathrm{F}}$ of PC is higher (lower) than the $E_{\mathrm{F}}$ of CC. Upward band bending creates an energetic upslope (Schottky barrier) for electron transfer but facilitates hole transfer from PC to CC, which encourages photo-oxidation reaction on CCs. ${ }^{149,152}$ On the contrary, downward band bending promotes electron transfer (ohmic contact) but hinders hole transfer from PC to CC, which is desirable for photo-reduction reaction. Therefore, proper energy level matching to minimize the barrier height or create an ohmic contact for specific carriers is vital for a maximum utilization of photogenerated carriers. Although nanosized CCs have limited capabilities for donating or accepting electrons, loading sufficient amount of CC NPs can still cause band bending in the semiconductor, which has been verified experimentally using Kelvin probe force microscopy and surface photovoltage measurements. ${ }^{150,151}$ For a CC with semiconductor-like properties, its band alignment with the PC and PE should also be considered to assess the charge transfer efficiency at their interface (Fig. 9b). ${ }^{\mathbf{1 4 9}}$
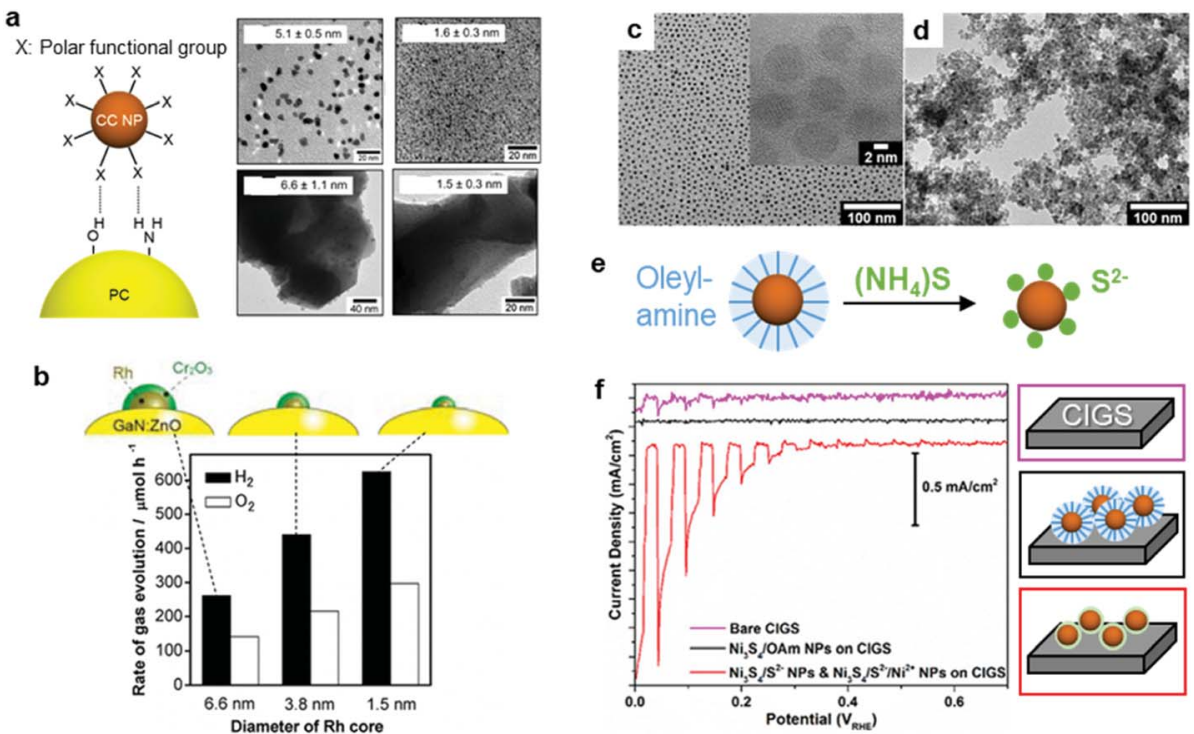

Fig. 7 (a) Hydrogen-bonding mediated NP adsorption on PC and size-controlled PVP-coated Rh NPs (top) and Rh NP-loaded GaN:ZnO after calcination treatment (bottom); (b) photocatalytic activity of $\mathrm{Cr}_{2} \mathrm{O}_{3}$ shell-coated Rh NPs/GaN:ZnO; (c) oleylamine coated-Ni $\mathrm{S}_{4} \mathrm{NPs}_{\text {; }}$ (d) $\mathrm{S}^{2-}$ stabilized $\mathrm{Ni}_{3} \mathrm{~S}_{4} \mathrm{NPs}$ obtained through (e) ligand exchange; (f) photocurrent scanning of bare, oleylamine coated-Ni $\mathrm{S}_{4}$, and $\mathrm{S}^{2-}$-stabilized $\mathrm{Ni}_{3} \mathrm{~S}_{4}$ $\mathrm{NP}$-loaded CdS/Cu(In,Ga)Se 2 PEs. Adapted with permission from (a and b) ref. 144, (c-f) ref. 147; copyright 2012 ACS and 2017 Wiley, respectively. 

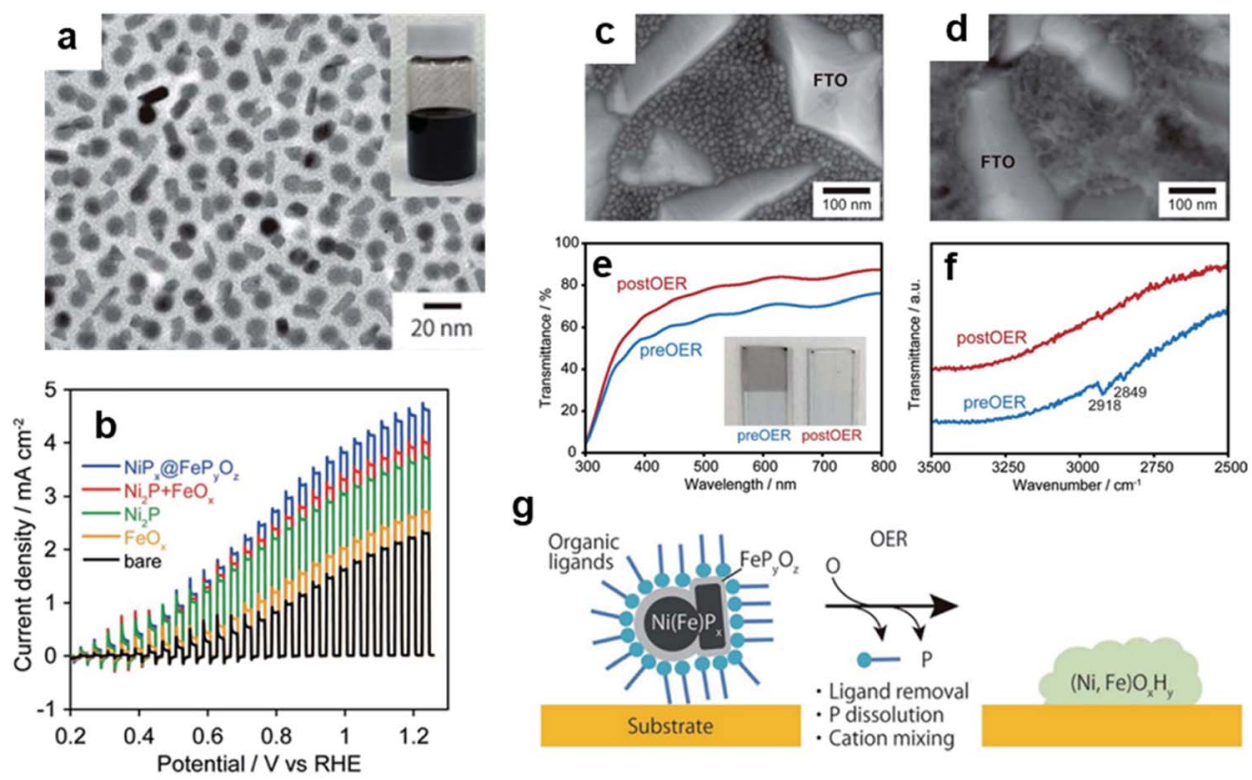

g

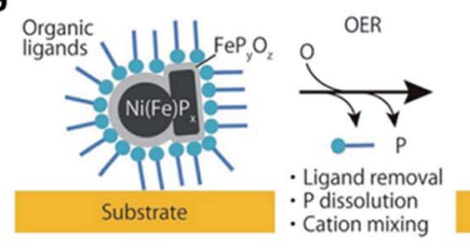

$(\mathrm{Ni}, \mathrm{Fe}) \mathrm{O}_{x} \mathrm{H}_{\mathrm{y}}$

Fig. 8 (a) TEM image of $\mathrm{NiP}_{x} @ \mathrm{aFeP}_{y} \mathrm{O}_{z} \mathrm{NPs}$; (b) photocurrent of $\mathrm{BiVO}_{4} \mathrm{PEs}$ with/without loading $\mathrm{NiP}_{x} \mathrm{aFeP}_{y} \mathrm{O}_{z} \mathrm{NPs}_{\text {; }} \mathrm{SEM}_{\text {images of }} \mathrm{NiP}_{x} @ \mathrm{aFeP} \mathrm{O}_{z}$ (c) before and (d) after CV on a fluorine-doped tin oxide (FTO) electrode; (e) transmittance spectra and (f) Fourier transform infrared (FTIR) spectra that confirm oleylamine ligand removal from $\mathrm{NiP}_{x} \mathrm{aFeP}_{y} \mathrm{O}_{z} \mathrm{NPs}$; $(\mathrm{g})$ schematic diagram illustrating the transformation of $\mathrm{NPs}_{\text {on }} \mathrm{BiVO}$. Adapted with permission from ref. 148; copyright 2018 RSC.

Chen et al. clearly demonstrated the beneficial effect of an appropriate $\mathrm{CC} / \mathrm{PC}$ junction on the photocatalytic activity by loading Pt or $\mathrm{MoS}_{2}$ CCs on the surface of CdS PCs. ${ }^{153}$ Although Pt has a higher HER activity than $\mathrm{MoS}_{2}$ as an EC (Fig. 9c), the photocatalytic HER activity of the $\mathrm{MoS}_{2}$-loaded CdS was superior to that of the Pt-loaded CdS (Fig. 9d). This observation arose from the differences in their electron transfer rates. Specifically, the deeper $E_{\mathrm{F}}$ of Pt caused a greater upward band bending effect in CdS, which simultaneously disturbed the photoexcited electron transfer from CdS to Pt. This suggests that a lower activation potential for electron transfer from CdS makes $\mathrm{MoS}_{2}$ more suitable as a CC than Pt (Fig. 9e). Therefore, the relative performances of ECs do not necessarily reflect their relative applicability as CCs. a
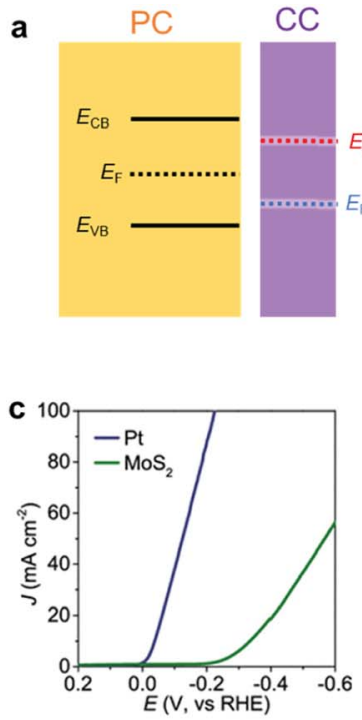
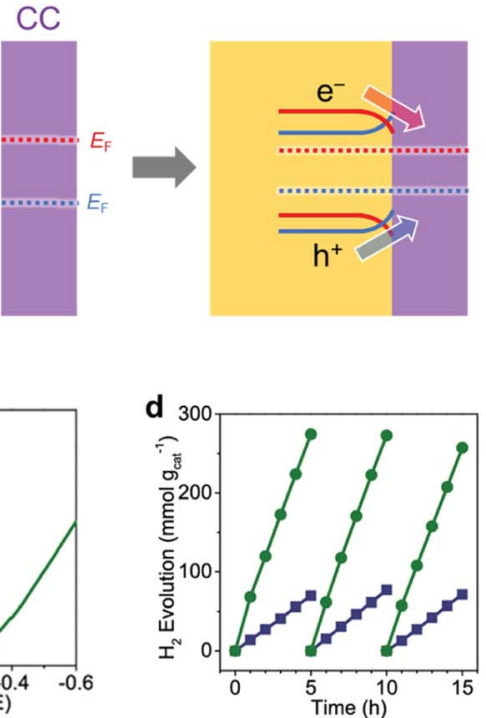

b

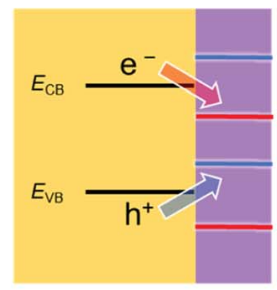

e

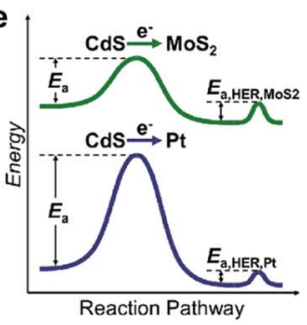

Fig. 9 Energy level matching of a PC semiconductor with a CC for (a) metal CC and (b) semiconductor CC [red and blue cases create ohmic contact (Schottky barrier) for photogenerated electrons (holes) and holes (electrons), respectively]; (c) CV comparison of electrochemical HER activity of Pt and $\mathrm{MoS}_{2}$ ECs in $0.5 \mathrm{M} \mathrm{H}_{2} \mathrm{SO}_{4}$; (d) photocatalytic HER activity of Pt/CdS and $\mathrm{MoS}_{2} / \mathrm{CdS}$ composites under visible-light (>400 nm) irradiation; (e) schematic reaction profile showing the activation energy from light absorption to $\mathrm{H}_{2}$ evolution. Adapted with permission from (ce) ref. 153; copyright 2019 ACS. 
To evaluate the carrier transfer efficiency at $\mathrm{CC} /$ semiconductor junctions, key parameters (e.g., work function of the metal CC, $E_{\mathrm{F}}$ of the semiconductor) deserve deeper investigations. In the case of metals, standard work function data can be used to estimate the bending direction and Schottky barrier height at CC/PC junctions; in contrast, $E_{\mathrm{F}}$ and bandgap values for complex heterogeneous CCs are not readily available, which makes evaluations of their band alignment difficult. Nevertheless, DFT and first-principle calculations can provide critical insights on the fundamental electronic structure of EC materials (including band structure, density of states and $E_{\mathrm{F}}$ ), enabling rapid prediction of suitable PC/CC combinations.

Even if the interfacial band alignments are unknown, the interfacial carrier dynamics can be measured through optical experiments, which can be used to assess the PC/CC interface. ${ }^{154}$ Transient absorption spectroscopy (TAS) monitors the photogenerated carrier dynamics in a PC by recording the temporal absorption evolution after a pulse excitation. ${ }^{\mathbf{1 5 5}}$ For example, TAS reveals (i) how electrons at the conduction band minimum behave in a PC/CC composite after photoexcitation and (ii) the subsequent ultrafast intraband relaxation of hot electrons by probing the absorption in the infrared region derived from free electrons. ${ }^{\mathbf{1 5 5 , 1 5 6}}$ Although TAS has been conducted on clear quantum-dot dispersions, TAS measurements for solid-state bulk materials in reflectance mode are still uncommon. Yamakata et al. showed how Pt and $\mathrm{CoO}_{x}$ CCs affected the carrier dynamics when deposited on an $\mathrm{LaTiO}_{2} \mathrm{~N}$ PC in the solid state. ${ }^{157}$ Upon $\mathrm{CoO}_{x}$ loading, visible $\left(17000 \mathrm{~cm}^{-1}\right)$ and IR $\left(2000 \mathrm{~cm}^{-1}\right)$ probes traced a temporal decrease and increase in the population of holes and free electrons in $\mathrm{LaTiO}_{2} \mathrm{~N}$, respectively, after a $500 \mathrm{~nm}$ laser pulse excitation (Fig. 10). These results indicated that $\mathrm{CoO}_{x}$ can rapidly extract photogenerated holes in $\mathrm{LaTiO}_{2} \mathrm{~N}$ to dramatically extend the lifetime of electrons. In contrast, Pt could not effectively extract photogenerated electrons because of the trapping mechanism
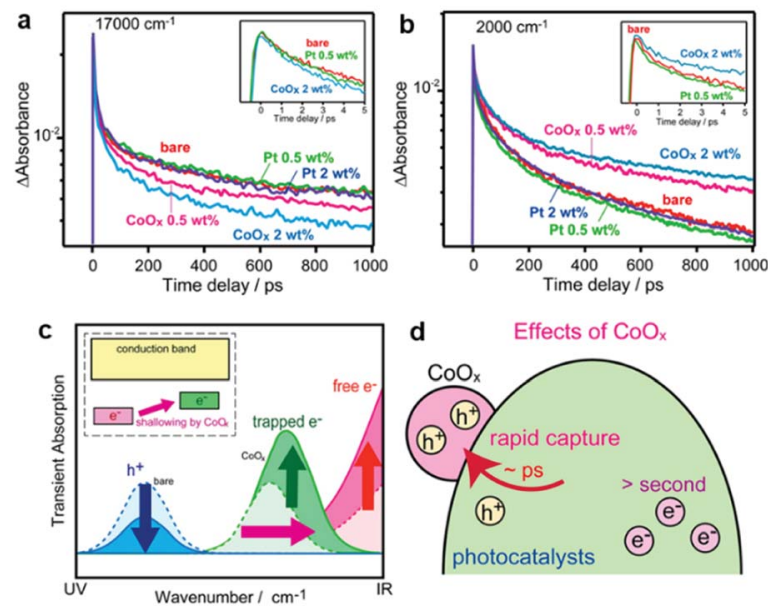

Fig. 10 Decay of transient absorption at (a) $17000 \mathrm{~cm}^{-1}$ and (b) $2000 \mathrm{~cm}^{-1}$ for bare, $\mathrm{CoO}_{x}$-loaded, and Pt-loaded $\mathrm{LaTiO}_{2} \mathrm{~N}$ after excited by $500 \mathrm{~nm}$ laser pulses; (c and d) schematics showing the change in carrier dynamics upon $\mathrm{CoO}_{x} \mathrm{CC}$ loading. Adapted with permission from ref. 157; copyright 2014 ACS. occurring at mid-gap states in the $\mathrm{LaTiO}_{2} \mathrm{~N}$. These TAS findings help pinpoint which specific process is the bottleneck in attaining excellent activity. Therefore, applying ultrafast spectroscopy to $\mathrm{CC} / \mathrm{PC}(\mathrm{PE})$ systems could be very useful in providing guidelines for designing CC materials.

\subsection{Assessment of CC activity}

In addition to the interfacial carrier dynamics, the intrinsic electrocatalytic activity of the CC material is still a significant descriptor of photocatalytic and PEC performance. Since the CCs serve as highly-active sites to drive redox reactions (like ECs), an understanding and evaluation of their intrinsic HER and OER activities are requisite for enhancing the catalytic performance. Notably, their catalytic activities can be measured with a CCloaded electrode using an electrochemical system. In EC studies, the catalytic activities are typically monitored under strong acidic or alkaline conditions, which are advantageous in showing their maximum activities. However, such extreme $\mathrm{pH}$ conditions cannot be applied in photocatalytic and PEC systems because they would likely cause chemical damage to the semiconductor. ${ }^{158}$ Since the stability of the photoactive semiconductor is the top priority for water splitting, it is important to conduct assessments at a practically-applicable pH. Even if an EC exhibits excellent performance

a

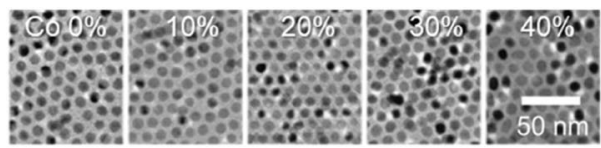

b

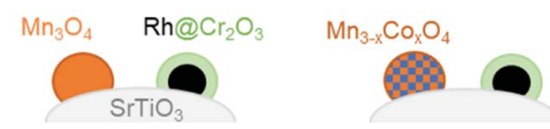

C
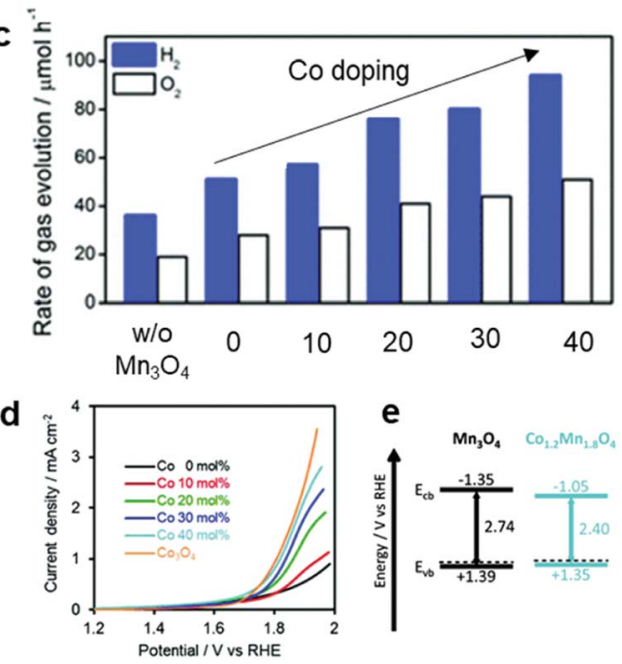

Fig. 11 Co-doping effect on the overall water-splitting activity of $\mathrm{SrTiO}_{3}$ : (a) TEM images of $\mathrm{Mn}_{3} \mathrm{O}_{4}$ doped with various Co concentrations; (b) schematic of CC-loaded photocatalyst; (c) photocatalytic trend as a function of $\mathrm{Co}$ dopant concentration in $\mathrm{Mn}_{3} \mathrm{O}_{4} \mathrm{CCs}$; (d) electrochemical OER activities of $\mathrm{Co}_{x} \mathrm{Mn}_{3-x} \mathrm{O}_{4} \mathrm{NPs}$ in a neutral electrolyte (0.1 M PBS); (e) calculated band structures of $\mathrm{Mn}_{3} \mathrm{O}_{4}$ and $\mathrm{Co}_{x} \mathrm{Mn}_{3-x} \mathrm{O}_{4} \mathrm{NPs}$. Adapted with permission from ref. 145; copyright 2018 RSC. 
under specific $\mathrm{pH}$ conditions, that same material might not be equally effective as CCs under different $\mathrm{pH}$ conditions. ${ }^{159}$ Therefore, it is necessary to examine the CC performance in an environment similar to that optimized for the photocatalytic and PEC systems. For example, based on the synergistic improvement of OER activity by a bimetallic Co-Mn oxide EC, ${ }^{\mathbf{1 6 0}}$ our group investigated the effect of Co doping on the catalytic OER activity of $\mathrm{Mn}_{3} \mathrm{O}_{4}$ NPs on the $\mathrm{SrTiO}_{3} \mathrm{PC}$, and found that increasing the Co doping content improved the water-splitting activity (Fig. 11). ${ }^{145}$ By measuring the OER activity of a $\mathrm{Co}_{x} \mathrm{Mn}_{3-x} \mathrm{O}_{4}$ NP-loaded electrode in neutral $\mathrm{pH}$ [0.1 $\mathrm{M}$ phosphate buffer solution (PBS)], we found that the Co content monotonically enhanced the OER activity (Fig. 11d). The calculated band structure of the $\mathrm{Co}_{x} \mathrm{Mn}_{3-x} \mathrm{O}_{4}$ NPs had similar valence band levels, regardless of the Co content, which indicated that the enhanced OER kinetics achieved by the Co-doping in $\mathrm{Mn}_{3} \mathrm{O}_{4}$ CC primarily contributed to boosting the overall photocatalytic water-splitting activity by accelerating slow OER process (Fig. 11e). Electrochemical assessments under similar conditions as those used for the photocatalytic and PEC systems can offer more accurate predictions of an EC's suitability as a CC. Recently reported ECs that are active over universal $\mathrm{pH}$ represent promising candidates as CCs in various photocatalytic and PEC environments. ${ }^{161-163}$

\subsection{Prevention of backward reaction}

The oxygen reduction reaction (ORR) is usually not an issue to consider for electrochemical systems because they employ a divided cell configuration, wherein the HER and OER
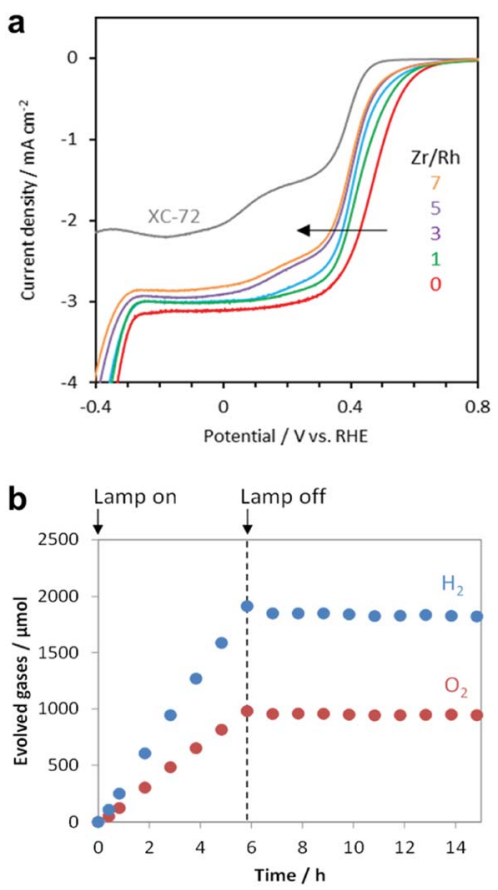

Fig. 12 (a) Current-potential curves of $\mathrm{RhZrO}_{x}(\mathrm{Zr} / \mathrm{Rh}: 0-7 \mathrm{w} / \mathrm{w})$ loaded carbon supports in $\mathrm{O}_{2}$-saturated $1 \mathrm{M} \mathrm{Na}_{2} \mathrm{SO}_{4}$ (pH 7); (b) gas evolution over time by $\mathrm{RhZrO}_{x} / \mathrm{SrTiO}_{3}: \mathrm{Al}(\mathrm{Rh}=0.1 \mathrm{wt} \%$ and $\mathrm{Zr}=$ 0.5 wt\% vs. $\mathrm{SrTiO}_{3}$ : Al) during and after light irradiation $(300 \mathrm{~W}$ Xe lamp). Adapted with permission from ref. 169; copyright 2020 RSC. electrodes are placed in separated cells. However, the ORR must be considered in overall water splitting using powdered PCs because both half-reactions take place in a single reactor. Outstanding HER CCs, such as Pt and Rh metals, tend to actively catalyse the ORR, ${ }^{22}$ which consumes the $\mathrm{H}_{2}$ and $\mathrm{O}_{2}$ evolved during the photocatalysis, thus reducing the $\mathrm{H}_{2}$ uptake. ${ }^{164}$ Strategies to effectively suppress this backward reaction and increase the quantity of evolved $\mathrm{H}_{2}$ include the application of protective coatings on the CCs (e.g., amorphous oxides such as $\mathrm{CrO}_{x}{ }^{165} \mathrm{TaO}_{x}{ }^{166} \mathrm{SiO}_{x},{ }^{167}$ and $\mathrm{ZrO}_{x}$ (ref. 168 and 169)). Our electrochemical measurements demonstrated that the $\mathrm{ZrO}_{x}$ matrix could suppress the ORR of $\mathrm{Rh}^{3+}$ active sites, which confirmed the $\mathrm{O}_{2}$-blocking ability of $\mathrm{ZrO}_{x}$ (Fig. 12a) and prevented the loss of $\mathrm{H}_{2}$-uptake in photocatalytic overall water splitting by $\mathrm{ZrRhO}_{x} /$ $\mathrm{SrTiO}_{3}$ :Al (Fig. 12b). Evaluating the ORR activities of CC materials in addition to their HER and OER activities can provide insights relevant for improving the total photocatalytic activity.

\subsection{Structural and chemical transformations of CCs during photocatalysis}

Similar to ECs, nanosized CCs can undergo structural and chemical transformations during photocatalytic and PEC water-
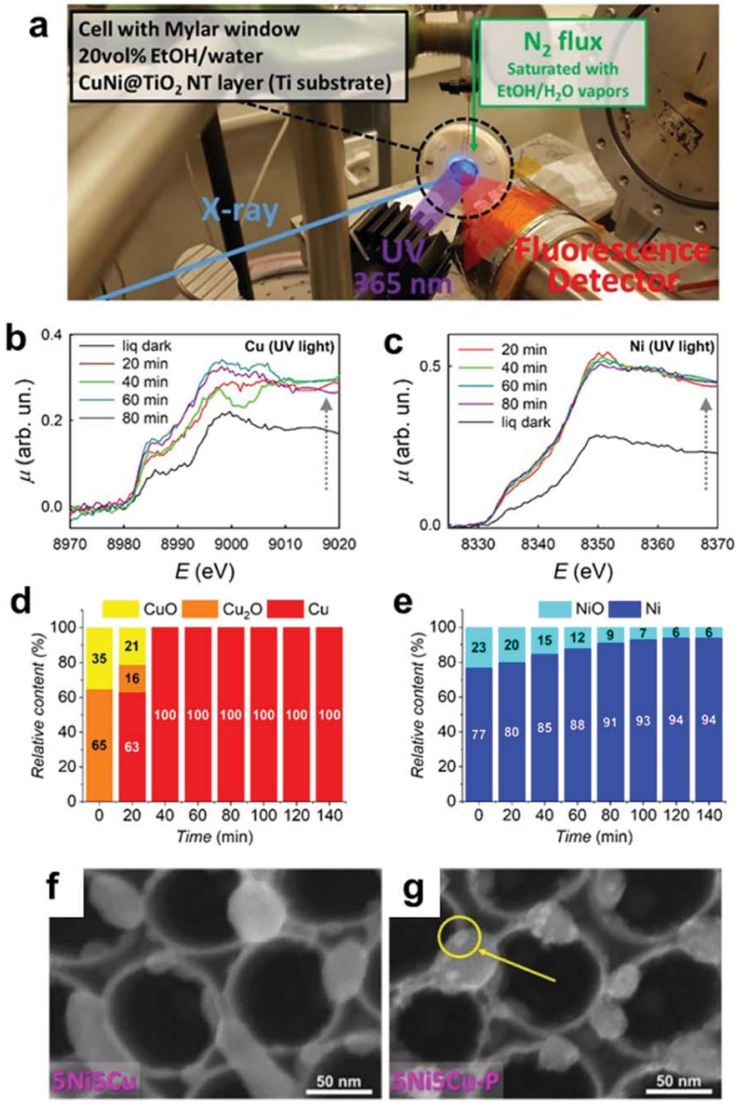

Fig. 13 (a) Operando XAS experimental setup; (b) Cu K-edge and (c) Ni $\mathrm{K}$-edge XAS spectra of $5 \mathrm{Ni} 5 \mathrm{Cu}-\mathrm{TiO}_{2}$ in a water-ethanol under UV irradiation for various exposure times; (d) $\mathrm{Cu}$ and (e) Ni phase contents determined by operando XAS for $5 \mathrm{Ni5Cu}-\mathrm{TiO}_{2}$; $\mathrm{SEM}$ images of $5 \mathrm{Ni} 5 \mathrm{Cu}-\mathrm{TiO}_{2}(\mathrm{f})$ before and $(\mathrm{g}$ ) after photocatalysis (a yellow circle indicates metallic NPs deposited under the UV irradiation). Adapted with permission from ref. 171; copyright 2020 ACS. 
splitting. In fact, our group's study revealed that the $\mathrm{NiP}_{x}$ @$\mathrm{FeP}_{y} \mathrm{O}_{z}$ CCs on $\mathrm{BiVO}_{4} \mathrm{PE}$ transformed into $\mathrm{NiFeOOH}$ based on post-OER characterizations with X-ray photoelectron spectroscopy (XPS) and Fourier transform infrared spectroscopy (FTIR). ${ }^{148}$ We also observed a compositional change in the novel $\mathrm{Rh}-\mathrm{Cl}-\mathrm{Zr}-\mathrm{O}$ CCs deposited on $\mathrm{SrTiO}_{3}$ :Al PCs under operating conditions. After the photocatalysis, XPS analyses detected the removal of $\mathrm{Cl}$ from the initial $\mathrm{Rh}-\mathrm{Cl}-\mathrm{Zr}-\mathrm{O} \mathrm{CC}$ to form $\mathrm{RhZrO}_{x}$ during photocatalysis. ${ }^{169}$ These results indicated the importance of post-catalysis characterization in determining the actual active species. Additionally, in situ/operando characterization techniques are powerful tools for monitoring the temporal evolution of CCs under the relevant working conditions, and they can help us to deeply understand the transformation mechanism of CCs. ${ }^{\mathbf{1 7 0}}$ Recently, synchrotron-based characterizations have provided valuable data with high temporal resolution, even for a small concentration of CCs. Altomare and co-workers conducted operando X-ray absorption spectroscopy (XAS) experiments for CuNi CCs loaded onto $\mathrm{TiO}_{2}$ during photocatalysis (Fig. 13a). ${ }^{171}$ At the early stage of the reaction, the preformed $\mathrm{CuO}_{x}$ and $\mathrm{NiO}$ species were reduced to metallic $\mathrm{Cu}$ and $\mathrm{Ni}$, thus forming CuNi alloy CCs (Fig. 13b-e). Subsequently, the $\mathrm{H}_{2}$ evolution rate increased as the transformation progressed, which identified the metallic CuNi as the actual active sites. Operando XAS can also be used to confirm the stability of CCs in a sustained catalytic setting. Fundamentally, the integrated utilization of the methods discussed here is highly desirable to accelerate progress in designing highlyactive CC materials.

\section{Conclusions and outlook}

In this perspective, we have discussed recent developments in EC materials and their application as CCs in photocatalytic and PEC water-splitting systems. Although significant efforts have already been directed toward the construction of high-performance CC/ PC and CC/PEC composites, exploration of CC materials still lags its EC counterpart. If methodologies to properly hybridize active EC materials with a variety of photoactive semiconductors (including unstable chalcogenides and nitrides) are developed, the accumulated knowledge regarding ECs will dramatically accelerate advances in photocatalytic and PEC systems. We believe that the colloidal approach using NPs of active EC materials with controllable sizes and compositions represents a promising solution to bridge the studies of ECs and CCs.

However, there are urgent issues that must be overcome in order to further enhance their photocatalytic performance. For particulate PC systems, spatial separation of HER and OER sites is highly desirable to efficiently promote both half-reactions. Facet-selective photodeposition of HER and OER CCs has been realized on PCs (e.g., $\mathrm{SrTiO}_{3}: \mathrm{Al}$ and $\mathrm{BiVO}_{4}$ ) by utilizing the intrinsic built-in potential generated from the work function difference between the PC crystal planes. ${ }^{76,115}$ To realize such sitespecific CC deposition in other loading methods, exploiting the preferential adsorption of surfactants on different crystal planes of PCs could be useful. ${ }^{172}$ The surfactants on CC precursor complex or NP surface have functional groups that could interact with coordinatively unsaturated atoms on the PC surface via dynamic adsorption and desorption. Again, the distinct atomic arrangement on the crystal facets of PCs might affect the binding affinities of incoming functional groups. For example, the (111) surface of $\mathrm{Cu}_{2} \mathrm{O}$ PCs contains more $\mathrm{Cu}$ dangling bonds that can be passivated by polar functional ligands. ${ }^{173}$ In turn, CCs could be preferentially loaded on the exposed (100) surface of $\mathrm{Cu}_{2} \mathrm{O}$ through proper linker molecules. Likewise, $\mathrm{PtCl}_{6}{ }^{2-}$ interacted strongly with $\mathrm{OH}$ groups on the anatase $\mathrm{TiO}_{2}$ (101) surface, whereas $\mathrm{Pt}\left(\mathrm{NH}_{3}\right)_{4}{ }^{2+}$ does not. ${ }^{174}$ As such, this strategy can only be implemented on limited PCs and CCs, thus expanding the library of applicable materials is of primary importance to improve the poor STH efficiencies in PC systems.

Another crucial factor that needs to be taken into account is the formation of an intimate interfacial contact between CCs and semiconductors. Although CCs are usually loaded on asprepared PC powder and PEs, the presence of pre-existing defective and/or insulative oxide layers on the semiconductor surface might cause charge recombination and/or carrier transfer blocking, and therefore should be removed before CC deposition. ${ }^{175}$ Acid treatment is a simple and effective way to dissolve such surface oxide layers. ${ }^{175}$

Ensuring long-term durability of CCs is also critical in maintaining excellent photocatalytic performance over extended operation periods. Since small amount of CCs is usually loaded on NPs or thin films, CC degradation can potentially occur during photocatalysis through dissolution and physical removal. ${ }^{125}$ The loss of carrier extraction capability of CCs could lead to self-corrosion of PCs due to uncompensated total charge. ${ }^{19}$ Employing newly developed efficient and durable multi-metallic compound EC materials as CCs is a straightforward but promising way in accelerating the discovery of high-performance PC/CC combinations. Aside from improving the chemical and physical durability, CC regeneration by feeding $\mathrm{CC}$ precursor during operation could be a logical solution in prolonging the lifetime of practical photocatalytic systems. ${ }^{176}$

As stated from Section 3, the need to control the CC morphology, internal electronic structure, and intrinsic surface catalytic activity, in addition to the CC's interfacial structure with the semiconductors, make advancements in this field challenging. However, recent advances in characterization techniques such as ultrafast spectroscopy and synchrotronbased in situ analyses have gradually revealed the crucial role of such factors in determining the bottlenecks of photocatalytic systems. In addition to developing these technologies, acquiring fundamental properties from basic electrocatalytic analysis and theoretical DFT and $a b$ initio calculation can potentially contribute to the understanding and construction of a sustainable and highly-efficient solar-driven photocatalytic water-splitting system.

\section{Author contributions}

MS conceived the topic and structure of the work. All the authors contributed to the discussion, writing, editing, and revision of this work. 


\section{Conflicts of interest}

There are no conflicts to declare.

\section{Acknowledgements}

This work was partly supported by the Artificial Photosynthesis Project of the New Energy and Industrial Technology Development Organization (NEDO) of Japan and Japan Society for the Promotion of Science (JSPS) KAKENHI for Scientific Research S (Grant No. JP19H0563) (T. T.), and Challenging Research (Exploratory) (Grant No. JP20K21236) (M. S.). We thank Suzanne Adam, PhD, from Edanz (https://jp.edanz.com/ac) for editing a draft of this manuscript.

\section{References}

1 T. M. L. Wigley, Clim. Chang., 2017, 147, 31-45.

2 S. C. Peter, ACS Energy Lett, 2018, 3, 1557-1561.

3 N. Sánchez-Bastardo, R. Schlögl and H. Ruland, Ind. Eng. Chem. Res., 2021, 60, 11855-11881.

4 Y. Nonobe, IEEJ Trans. Electr. Electron. Eng., 2017, 12, 5-9. 5 U. P. M. Ashik, W. M. A. Wan Daud and H. F. Abbas, Renew. Sustain. Energy Rev., 2015, 44, 221-256.

6 S. Dutta, Energy Fuels, 2021, 35, 11613-11639.

7 M. R. Shaner, H. A. Atwater, N. S. Lewis and E. W. McFarland, Energy Environ. Sci., 2016, 9, 2354-2371.

8 J. Jia, L. C. Seitz, J. D. Benck, Y. Huo, Y. Chen, J. W. D. Ng, T. Bilir, J. S. Harris and T. F. Jaramillo, Nat. Commun., 2016, 7, 1-6.

9 S. Wang, A. Lu and C.-J. Zhong, Nano Convergence, 2021, 8, 1-23.

10 Q. Wang and K. Domen, Chem. Rev., 2019, 120, 919-985.

11 D. Kang, T. W. Kim, S. R. Kubota, A. C. Cardiel, H. G. Cha and K.-S. Choi, Chem. Rev., 2015, 115, 12839-12887.

12 T. Hisatomi and K. Domen, Nat. Catal., 2019, 2, 387-399.

13 H. Nishiyama, T. Yamada, M. Nakabayashi, Y. Maehara, M. Yamaguchi, Y. Kuromiya, H. Tokudome, S. Akiyama, T. Watanabe, R. Narushima, S. Okunaka, N. Shibata, T. Takata, T. Hisatomi and K. Domen, Nature, 2021, 598, 304-307.

14 C. Jiang, S. J. A. Moniz, A. Wang, T. Zhang and J. Tang, Chem. Soc. Rev., 2017, 46, 4645-4660.

15 H. Wu, H. L. Tan, C. Y. Toe, J. Scott, L. Wang, R. Amal and Y. H. Ng, Adv. Mater., 2020, 32, 1-21.

16 T. Higashi, H. Nishiyama, Y. Suzuki, Y. Sasaki, T. Hisatomi, M. Katayama, T. Minegishi, K. Seki, T. Yamada and K. Domen, Angew. Chem., Int. Ed., 2019, 58, 2300-2304.

17 J. Yang, D. Wang, H. Han and C. Li, Acc. Chem. Res., 2013, 46, 1900-1909.

18 K. Takanabe, ACS Catal., 2017, 7, 8006-8022.

19 X. Ning and G. Lu, Nanoscale, 2020, 12, 1213-1223.

20 J. Ran, J. Zhang, J. Yu, M. Jaroniec and S. Z. Qiao, Chem. Soc. Rev., 2014, 43, 7787-7812.

21 W. Qiao, H. B. Tao, B. Liu and J. Chen, Small, 2019, 15, 1804391.
22 Z. W. Seh, J. Kibsgaard, C. F. Dickens, I. Chorkendorff, J. K. Nørskov and T. F. Jaramillo, Science, 2017, 355, 6321.

23 J. Zhu, L. Hu, P. Zhao, L. Y. S. Lee and K. Y. Wong, Chem. Rev., 2020, 120, 851-918.

24 J. Song, C. Wei, Z.-F. Huang, C. Liu, L. Zeng, X. Wang and Z. J. Xu, Chem. Soc. Rev., 2020, 49, 2196-2214.

25 J. K. Nørskov, T. Bligaard, A. Logadottir, J. R. Kitchin, J. G. Chen, S. Pandelov and U. Stimming, J. Electrochem. Soc., 2005, 152, J23.

26 T. F. Jaramillo, K. P. Jørgensen, J. Bonde, J. H. Nielsen, S. Horch and I. Chorkendorff, Science, 2007, 317, 100-102.

27 P. Liu, J. Zhu, J. Zhang, P. Xi, K. Tao, D. Gao and D. Xue, ACS Energy Lett, 2017, 2, 745-752.

28 Y. Chen, K. Yang, B. Jiang, J. Li, M. Zeng and L. Fu, J. Mater. Chem. A, 2017, 5, 8187-8208.

29 S. M. El-Refaei, P. A. Russo and N. Pinna, ACS Appl. Mater. Interfaces, 2021, 13, 22077-22097.

30 Y. Jiang and Y. Lu, Nanoscale, 2020, 12, 9327-9351.

31 M. Kuang, W. Huang, C. Hegde, W. Fang, X. Tan, C. Liu, J. Ma and Q. Yan, Mater. Horizons, 2020, 7, 32-53.

32 G. Fu and J.-M. Lee, J. Mater. Chem. A, 2019, 7, 9386-9405.

33 C. Tang, L. Gan, R. Zhang, W. Lu, X. Jiang, A. M. Asiri, X. Sun, J. Wang and L. Chen, Nano Lett., 2016, 16, 66176621.

34 I. H. Kwak, I. S. Kwon, T. T. Debela, H. G. Abbas, Y. C. Park, J. Seo, J.-P. Ahn, J. H. Lee, J. Park and H. S. Kang, ACS Nano, 2020, 14, 11995-12005.

35 A. A. Rezaie, E. Lee, D. Luong, J. A. Yapo and B. P. T. Fokwa, ACS Mater. Lett., 2021, 3, 313-319.

36 S. H. Park, T. H. Jo, M. H. Lee, K. Kawashima, C. B. Mullins, H.-K. Lim and D. H. Youn, J. Mater. Chem. A, 2021, 9, 49454951.

37 X. Zheng, Y. Chen, X. Bao, S. Mao, R. Fan and Y. Wang, ACS Catal., 2020, 10, 11634-11642.

38 S. Zhao, J. Berry-Gair, W. Li, G. Guan, M. Yang, J. Li, F. Lai, F. Corà, K. Holt, D. J. L. Brett, G. He and I. P. Parkin, Adv. Sci., 2020, 7, 1903674.

39 T. Naito, T. Shinagawa, T. Nishimoto and K. Takanabe, Inorg. Chem. Front., 2021, 8, 2900-2917.

40 H. Over, ACS Catal., 2021, 11, 8848-8871.

41 P. M. Bodhankar, P. B. Sarawade, G. Singh, A. Vinu and D. S. Dhawale, J. Mater. Chem. A, 2021, 9, 3180-3208.

42 M. E. C. Pascuzzi, A. J. W. Man, A. Goryachev, J. P. Hofmann and E. J. M. Hensen, Catal. Sci. Technol., 2020, 10, 55935601.

43 I. C. Man, H.-Y. Su, F. Calle-Vallejo, H. A. Hansen, J. I. Martínez, N. G. Inoglu, J. Kitchin, T. F. Jaramillo, J. K. Nørskov and J. Rossmeisl, ChemCatChem, 2011, 3, 1159-1165.

44 B. Zhang, X. Zheng, O. Voznyy, R. Comin, M. Bajdich, M. García-Melchor, L. Han, J. Xu, M. Liu, L. Zheng, F. P. G. de Arquer, C. T. Dinh, F. Fan, M. Yuan, E. Yassitepe, N. Chen, T. Regier, P. Liu, Y. Li, P. De Luna, A. Janmohamed, H. L. Xin, H. Yang, A. Vojvodic and E. H. Sargent, Science, 2016, 352, 333-337. 
45 S. Kim, H. Mizuno, M. Saruyama, M. Sakamoto, M. Haruta, H. Kurata, T. Yamada, K. Domen and T. Teranishi, Chem. Sci., 2020, 11, 1523-1530.

46 S. Anantharaj, S. R. Ede, K. Sakthikumar, K. Karthick, S. Mishra and S. Kundu, ACS Catal., 2016, 6, 8069-8097.

47 T. Zhang, Y. Zhu and J. Y. Lee, J. Mater. Chem. A, 2018, 6, 8147-8158.

48 X. Shang, J.-H. Tang, B. Dong and Y. Sun, Sustain. Energy Fuels, 2020, 4, 3211-3228.

49 G. Zhang, Y. Li, X. Xiao, Y. Shan, Y. Bai, H.-G. Xue, H. Pang, Z. Tian and Q. Xu, Nano Lett., 2021, 21, 3016-3025.

50 D. Guan, G. Ryu, Z. Hu, J. Zhou, C.-L. Dong, Y.-C. Huang, K. Zhang, Y. Zhong, A. C. Komarek, M. Zhu, X. Wu, C.-W. Pao, C.-K. Chang, H.-J. Lin, C.-T. Chen, W. Zhou and Z. Shao, Nat. Commun., 2020, 11, 3376.

51 M. Cui, C. Yang, B. Li, Q. Dong, M. Wu, S. Hwang, H. Xie, X. Wang, G. Wang and L. Hu, Adv. Energy Mater., 2021, 11, 2002887.

52 F. Dionigi and P. Strasser, Adv. Energy Mater., 2016, 6, 1600621.

53 D. Liu, H. Ai, J. Li, M. Fang, M. Chen, D. Liu, X. Du, P. Zhou, F. Li, K. H. Lo, Y. Tang, S. Chen, L. Wang, G. Xing and H. Pan, Adv. Energy Mater., 2020, 10, 2002464.

54 M. Y. Zu, C. Wang, L. Zhang, L. R. Zheng and H. G. Yang, Mater. Horizons, 2019, 6, 115-121.

55 Y. Zhu, W. Zhou, Y. Zhong, Y. Bu, X. Chen, Q. Zhong, M. Liu and Z. Shao, Adv. Energy Mater., 2017, 7, 1602122.

56 D. Wu, K. Kusada, S. Yoshioka, T. Yamamoto, T. Toriyama, S. Matsumura, Y. Chen, O. Seo, J. Kim, C. Song, S. Hiroi, O. Sakata, T. Ina, S. Kawaguchi, Y. Kubota, H. Kobayashi and H. Kitagawa, Nat. Commun., 2021, 12, 1145.

57 J. Zhang, T. Wang, D. Pohl, B. Rellinghaus, R. Dong, S. Liu, X. Zhuang and X. Feng, Angew. Chem., Int. Ed., 2016, 55, 6702-6707.

58 H. Xu, J. Wei, K. Zhang, Y. Shiraishi and Y. Du, ACS Appl. Mater. Interfaces, 2018, 10, 29647-29655.

59 C. Zhu, Z. Yin, W. Lai, Y. Sun, L. Liu, X. Zhang, Y. Chen and S. L. Chou, Adv. Energy Mater., 2018, 8, 1802327.

60 J. Jiang, Q. Liu, C. Zeng and L. Ai, J. Mater. Chem. A, 2017, 5, 16929-16935.

61 B. Xiong, L. Chen and J. Shi, ACS Catal., 2018, 8, 3688-3707. 62 C. C. L. McCrory, S. Jung, J. C. Peters and T. F. Jaramillo, J. Am. Chem. Soc., 2013, 135, 16977-16987.

63 M. Wang, L. Zhang, Y. He and H. Zhu, J. Mater. Chem. A, 2021, 9, 5320-5363.

64 Y. Garsany, O. A. Baturina, K. E. Swider-Lyons and S. S. Kocha, Anal. Chem., 2010, 82, 6321-6328.

65 N. K. Chaudhari, H. Jin, B. Kim and K. Lee, Nanoscale, 2017, 9, 12231-12247.

66 Y. Garsany, O. A. Baturina, K. E. Swider-Lyons and S. S. Kocha, Anal. Chem., 2010, 82, 6321-6328.

67 C. Zhu, Q. Shi, S. Feng, D. Du and Y. Lin, ACS Energy Lett, 2018, 3, 1713-1721.

68 M. B. Stevens, L. J. Enman, A. S. Batchellor, M. R. Cosby, A. E. Vise, C. D. M. Trang and S. W. Boettcher, Chem. Mater., 2016, 29, 120-140.

69 S. Jin, ACS Energy Lett, 2017, 2, 1937-1938.
70 W. Li, D. Xiong, X. Gao and L. Liu, Chem. Commun., 2019, 55, 8744-8763.

71 P. Chen, K. Xu, Z. Fang, Y. Tong, J. Wu, X. Lu, X. Peng, H. Ding, C. Wu and Y. Xie, Angew. Chem., Int. Ed., 2015, 54, 14710-14714.

72 W. Cai, R. Chen, H. Yang, H. B. Tao, H.-Y. Wang, J. Gao, W. Liu, S. Liu, S.-F. Hung and B. Liu, Nano Lett., 2020, 20, 4278-4285.

73 J. Xiao, J. J. M. Vequizo, T. Hisatomi, J. Rabeah, M. Nakabayashi, Z. Wang, Q. Xiao, H. Li, Z. Pan, M. Krause, N. Yin, G. Smith, N. Shibata, A. Brückner, A. Yamakata, T. Takata and K. Domen, J. Am. Chem. Soc., 2021, 143, 10059-10064.

74 S. Bai, W. Yin, L. Wang, Z. Li and Y. Xiong, RSC Adv., 2016, 6, 57446-57463.

75 Y. Hosogi, Y. Shimodaira, H. Kato, H. Kobayashi and A. Kudo, Chem. Mater., 2008, 20, 1299-1307.

76 T. Takata, J. Jiang, Y. Sakata, M. Nakabayashi, N. Shibata, V. Nandal, K. Seki, T. Hisatomi and K. Domen, Nature, 2020, 581, 411-414.

77 J. Zhao, B. Fu, X. Li, Z. Ge, B. Ma and Y. Chen, ACS Appl. Energy Mater., 2020, 3, 10910-10919.

78 D. Ren, Z. Z. Liang, Y. H. Ng, P. Zhang, Q. Xiang and X. Li, Chem. Eng. J., 2020, 390, 124496.

79 X. Lu, J. Xie, S. Liu, A. Adamski, X. Chen and X. Li, ACS Sustain. Chem. Eng., 2018, 6, 13140-13150.

80 L. Tian, S. Min, F. Wang and Z. Zhang, J. Phys. Chem. C, 2019, 123, 28640-28650.

81 D. Ren, Z. Z. Liang, Y. H. Ng, P. Zhang, Q. Xiang and X. Li, Chem. Eng. J., 2020, 390, 124496.

82 J. Zhang, W. Yao, C. Huang, P. Shi and Q. Xu, J. Mater. Chem. A, 2017, 5, 12513-12519.

83 Z. Qin, Y. Chen, Z. Huang, J. Su and L. Guo, J. Mater. Chem. A, 2017, 5, 19025-19035.

84 C. Cheng, S. Zong, J. Shi, F. Xue, Y. Zhang, X. Guan, B. Zheng, J. Deng and L. Guo, Appl. Catal. B Environ., 2020, 265, 118620.

85 W. Zhong, W. Tu, S. Feng and A. Xu, J. Alloys Compd., 2019, 772, 669-674.

86 R. M. Irfan, M. H. Tahir, S. Iqbal, M. Nadeem, T. Bashir, M. Maqsood, J. Zhao and L. Gao, J. Mater. Chem. C, 2021, 9, 3145-3154.

87 Z.-K. Shen, Y.-J. Yuan, P. Wang, W. Bai, L. Pei, S. Wu, Z.-T. Yu and Z. Zou, ACS Appl. Mater. Interfaces, 2020, 12, 17343-17352.

88 H. Du, H.-L. Guo, Y.-N. Liu, X. Xie, K. Liang, X. Zhou, X. Wang and A.-W. Xu, ACS Appl. Mater. Interfaces, 2016, 8, 4023-4030.

89 Y. Liu, B. Wang, Q. Zhang, S. Yang, Y. Li, J. Zuo, H. Wang and F. Peng, Green Chem., 2020, 22, 238-247.

90 X. Sun and H. Du, ACS Sustain. Chem. Eng., 2019, 7, 1632016328.

91 K. Chang, Z. Mei, T. Wang, Q. Kang, S. Ouyang and J. Ye, ACS Nano, 2014, 8, 7078-7087.

92 Y. Liu, B. Wang, Q. Zhang, S. Yang, Y. Li, J. Zuo, H. Wang and F. Peng, Green Chem., 2020, 22, 238-247. 
93 Y. Chao, J. Zheng, H. Zhang, Y. Ma, F. Li, Y. Tan and Z. Zhu, Energy Technol., 2018, 6, 2132-2138.

94 B. Ma, Y. Liu, J. Li, K. Lin, W. Liu and H. Zhan, Int. J. Hydrogen Energy, 2016, 41, 22009-22016.

95 X. Liang, J. Xie, J. Xiong, L. Gong and C. M. Li, Sustain. Energy Fuels, 2018, 2, 2053-2059.

96 Y. Pihosh, V. Nandal, T. Minegishi, M. Katayama, T. Yamada, K. Seki, M. Sugiyama and K. Domen, ACS Energy Lett, 2020, 5, 2492-2497.

97 X. Zong, J. Han, G. Ma, H. Yan, G. Wu and C. Li, J. Phys. Chem. C, 2011, 115, 12202-12208.

98 X. Zong, J. Han, G. Ma, H. Yan, G. Wu and C. Li, J. Phys. Chem. C, 2011, 115, 12202-12208.

99 J. Chu, G. Sun, X. Han, X. Chen, J. Wang, W. Hu, I. Waluyo, A. Hunt, Y. Du, B. Song and P. Xu, Nanoscale, 2019, 11, 15633-15640.

100 K. Maeda, K. Teramura, D. Lu, T. Takata, N. Saito, Y. Inoue and K. Domen, J. Phys. Chem. B, 2006, 110, 13753-13758.

101 E. Tsuji, R. Nanbu, Y. Degami, K. Hirao, T. Watanabe, N. Matsumoto, S. Suganuma and N. Katada, Part. Part. Syst. Charact., 2020, 37, 2000053.

102 Y. Negishi, Y. Matsuura, R. Tomizawa, W. Kurashige, Y. Niihori, T. Takayama, A. Iwase and A. Kudo, J. Phys. Chem. C, 2015, 119, 11224-11232.

103 L. Wei, Z. Liu, Z. Guo, M. Ruan, Y. Meng and W. Yan, ACS Appl. Energy Mater., 2021, 4, 7233-7241.

104 Z. Qin, Y. Chen, X. Wang, X. Guo and L. Guo, ACS Appl. Mater. Interfaces, 2016, 8, 1264-1272.

105 S. Meng, Y. Cui, H. Wang, X. Zheng, X. Fu and S. Chen, Dalton Trans., 2018, 47, 12671-12683.

106 S. Guan, X. Fu, Y. Zhang and Z. Peng, Chem. Sci., 2018, 9, 1574-1585.

107 X. L. Yin, L. L. Li, W. J. Jiang, Y. Zhang, X. Zhang, L. J. Wan and J. S. Hu, ACS Appl. Mater. Interfaces, 2016, 8, 1525815266.

108 X. Liu, Y. Zhao, X. Yang, Q. Liu, X. Yu, Y. Li, H. Tang and T. Zhang, Appl. Catal. B Environ., 2020, 275, 119144.

109 J. Dong, Y. Shi, C. Huang, Q. Wu, T. Zeng and W. Yao, Appl. Catal. B Environ., 2019, 243, 27-35.

110 X. Hong, X. Yu, L. Wang, Q. Liu, J. Sun and H. Tang, Inorg. Chem., 2021, 60, 12506-12516.

111 Y. Zhao, Y. Lu, L. Chen, X. Wei, J. Zhu and Y. Zheng, ACS Appl. Mater. Interfaces, 2020, 12, 46073-46083.

112 K. Wenderich and G. Mul, Chem. Rev., 2016, 116, 1458714619.

113 Z. Wang, Y. Inoue, T. Hisatomi, R. Ishikawa, Q. Wang, T. Takata, S. Chen, N. Shibata, Y. Ikuhara and K. Domen, Nat. Catal., 2018, 1, 756-763.

114 G. Ma, J. Liu, T. Hisatomi, T. Minegishi, Y. Moriya, M. Iwase, H. Nishiyama, M. Katayama, T. Yamada and K. Domen, Chem. Commun., 2015, 51, 4302-4305.

115 R. Li, F. Zhang, D. Wang, J. Yang, M. Li, J. Zhu, X. Zhou, H. Han and C. Li, Nat. Commun., 2013, 4, 1-7.

116 I. Vamvasakis, I. T. Papadas, T. Tzanoudakis, C. Drivas, S. A. Choulis, S. Kennou and G. S. Armatas, ACS Catal., 2018, 8, 8726-8738.
117 W. Liu, X. Wang, H. Yu and J. Yu, ACS Sustain. Chem. Eng., 2018, 6, 12436-12445.

118 Y. Dong, L. Kong, P. Jiang, G. Wang, N. Zhao, H. Zhang and B. Tang, ACS Sustain. Chem. Eng., 2017, 5, 6845-6853.

119 X. Lu, C. Ying Toe, F. Ji, W. Chen, X. Wen, R. J. Wong, J. Seidel, J. Scott, J. N. Hart and Y. H. Ng, ACS Appl. Mater. Interfaces, 2020, 12, 8324-8332.

120 S. Min, Y. Lei, H. Sun, J. Hou, F. Wang, E. Cui, S. She, Z. Jin, J. Xu and X. Ma, Mol. Catal., 2017, 440, 190-198.

121 T. Di, B. Zhu, J. Zhang, B. Cheng and J. Yu, Appl. Surf. Sci., 2016, 389, 775-782.

122 K.-Q. Lu, M.-Y. Qi, Z.-R. Tang and Y.-J. Xu, Langmuir, 2019, 35, 11056-11065.

123 F. E. Osterloh, Chem. Soc. Rev., 2013, 42, 2294-2320.

124 R. Hu, L. Meng, J. Zhang, X. Wang, S. Wu, Z. Wu, R. Zhou, L. Li, D. S. Li and T. Wu, Nanoscale, 2020, 12, 8875-8882.

125 Y. Pihosh, T. Minegishi, V. Nandal, T. Higashi, M. Katayama, T. Yamada, Y. Sasaki, K. Seki, Y. Suzuki, M. Nakabayashi, M. Sugiyama and K. Domen, Energy Environ. Sci., 2020, 13, 1519-1530.

126 X. Zhong, H. He, J. Du, Q. Ren, J. Huang, Y. Tang, J. Wang, L. Yang, F. Dong, L. Bian and Y. Zhou, Electrochim. Acta, 2019, 304, 301-311.

127 S. S. M. Bhat, S. A Lee, T. H. Lee, C. Kim, J. Park, T.-W. Lee, S. Y. Kim and H. W. Jang, ACS Appl. Energy Mater., 2020, 3, 5646-5656.

128 D. He, R. T. Gao, S. Liu, M. Sun, X. Liu, K. Hu, Y. Su and L. Wang, ACS Catal., 2020, 10, 10570-10576.

129 R. T. Gao, L. Wu, S. Liu, K. Hu, X. Liu, J. Zhang and L. Wang, J. Mater. Chem. A, 2021, 9, 6298-6305.

130 L. Wang, F. Dionigi, N. Truong Nguyen, R. Kirchgeorg, M. Gliech, S. Grigorescu, P. Strasser and P. Schmuki, Chem. Mater., 2015, 27, 2360-2366.

131 M. W. Kanan and D. G. Nocera, Science, 2008, 321, 10721075.

132 J. Zhang, Y. Huang, X. Lu, J. Yang and Y. Tong, ACS Sustain. Chem. Eng., 2021, 9, 8306-8314.

133 A. A. Haleem, S. Majumder, N. Perumandla, Z. N. Zahran and Y. Naruta, J. Phys. Chem. C, 2017, 121, 20093-20100.

134 J. Seo, T. Takata, M. Nakabayashi, T. Hisatomi, N. Shibata, T. Minegishi and K. Domen, J. Am. Chem. Soc., 2015, 137, 12780-12783.

135 Y. Gao, G. Yang, Y. Dai, X. Li, J. Gao, N. Li, P. Qiu and L. Ge, ACS Appl. Mater. Interfaces, 2020, 12, 17364-17375.

136 T. W. Kim and K. S. Choi, Science, 2014, 343, 990-994.

137 L. Wang, F. Dionigi, N. Truong Nguyen, R. Kirchgeorg, M. Gliech, S. Grigorescu, P. Strasser and P. Schmuki, Chem. Mater., 2015, 27, 2360-2366.

138 A. A. Haleem, N. Perumandla and Y. Naruta, ACS Omega, 2019, 4, 7815-7821.

139 J. Chang and E. R. Waclawik, RSC Adv., 2014, 4, 2350523527.

140 M. S. Bakshi, Cryst. Growth Des., 2015, 16, 1104-1133.

141 N. Sakamoto, H. Ohtsuka, T. Ikeda, K. Maeda, D. Lu, M. Kanehara, K. Teramura, T. Teranishi and K. Domen, Nanoscale, 2009, 1, 106-109. 
142 K. Maeda, N. Sakamoto, T. Ikeda, H. Ohtsuka, A. Xiong, D. Lu, M. Kanehara, T. Teranishi and K. Domen, Chem. -Eur. J., 2010, 16, 7750-7759.

143 K. Maeda, A. Xiong, T. Yoshinaga, T. Ikeda, N. Sakamoto, T. Hisatomi, M. Takashima, D. Lu, M. Kanehara, T. Setoyama, T. Teranishi and K. Domen, Angew. Chem., Int. Ed., 2010, 49, 4096-4099.

144 T. Ikeda, A. Xiong, T. Yoshinaga, K. Maeda, K. Domen and T. Teranishi, J. Phys. Chem. C, 2012, 117, 2467-2473.

145 T. Yoshinaga, M. Saruyama, A. Xiong, Y. Ham, Y. Kuang, R. Niishiro, S. Akiyama, M. Sakamoto, T. Hisatomi, K. Domen and T. Teranishi, Nanoscale, 2018, 10, 1042010427.

146 T. Kawawaki, Y. Kataoka, M. Hirata, Y. Iwamatsu, S. Hossain and Y. Negishi, Nanoscale Horizons, 2021, 6, 409-448.

147 S. Kim, T. Nishino, M. Saruyama, M. Sakamoto, H. Kobayashi, S. Akiyama, T. Yamada, K. Domen and T. Teranishi, ChemNanoMat, 2017, 3, 764-771.

148 M. Saruyama, S. Kim, T. Nishino, M. Sakamoto, M. Haruta, H. Kurata, S. Akiyama, T. Yamada, K. Domen and T. Teranishi, Chem. Sci., 2018, 9, 4830-4836.

149 T. Su, Q. Shao, Z. Qin, Z. Guo and Z. Wu, ACS Catal., 2018, 8, 2253-2276.

150 J. Zhu, S. Pang, T. Dittrich, Y. Gao, W. Nie, J. Cui, R. Chen, H. An, F. Fan and C. Li, Nano Lett., 2017, 17, 6735-6741.

151 R. Chen, F. Fan, T. Dittrich and C. Li, Chem. Soc. Rev., 2018, 47, 8238.

152 R. T. Tung, Appl. Phys. Rev., 2014, 1, 011304.

153 Z. Wang, N. Xue and J. Chen, J. Phys. Chem. C, 2019, 123, 24404-24408.

154 M. Yoshida, A. Yamakata, K. Takanabe, J. Kubota, M. Osawa and K. Domen, J. Am. Chem. Soc., 2009, 131, 13218-13219.

155 A. Yamakata and J. J. M. Vequizo, J. Photochem. Photobiol., C, 2019, 40, 234-243.

156 M. Okano, M. Sakamoto, T. Teranishi and Y. Kanemitsu, J. Phys. Chem. Lett., 2014, 5, 2951-2956.

157 A. Yamakata, M. Kawaguchi, N. Nishimura, T. Minegishi, J. Kubota and K. Domen, J. Phys. Chem. C, 2014, 118, 23897-23906.

158 F. M. Toma, J. K. Cooper, V. Kunzelmann, M. T. McDowell, J. Yu, D. M. Larson, N. J. Borys, C. Abelyan, J. W. Beeman, K. M. Yu, J. Yang, L. Chen, M. R. Shaner, J. Spurgeon, F. A. Houle, K. A. Persson and I. D. Sharp, Nat. Commun., 2016, 7, 1-11.
159 T. Takashima, K. Hashimoto and R. Nakamura, J. Am. Chem. Soc., 2012, 134, 1519-1527.

160 Z. Luo, E. Irtem, M. Ibáñez, R. Nafria, S. Martí-Sánchez, A. Genç, M. de la Mata, Y. Liu, D. Cadavid, J. Llorca, J. Arbiol, T. Andreu, J. Ramon Morante and A. Cabot, ACS Appl. Mater. Interfaces, 2016, 8, 17435-17444.

161 S. Zhang, X. Zhang, Y. Rui, R. Wang and X. Li, Green Energy Environ., 2021, 6, 458-478.

162 L. Zhang, H. Jang, H. Liu, M. G. Kim, D. Yang, S. Liu, X. Liu and J. Cho, Angew. Chem., Int. Ed., 2021, 60, 18821-18829.

163 L. Fu, X. Hu, Y. Li, G. Cheng and W. Luo, Nanoscale, 2019, 11, 8898-8905.

164 M. Yoshida, K. Takanabe, K. Maeda, A. Ishikawa, J. Kubota, Y. Sakata, Y. Ikezawa and K. Domen, J. Phys. Chem. C, 2009, 113, 10151-10157.

165 T. Takata, C. Pan, M. Nakabayashi, N. Shibata and K. Domen, J. Am. Chem. Soc., 2015, 137, 9627-9634.

166 J. A. Bau and K. Takanabe, ACS Catal., 2017, 7, 7931-7940. 167 S. Okunaka, H. Kameshige, T. Ikeda, H. Tokudome, T. Hisatomi, T. Yamada and K. Domen, ChemSusChem, 2020, 13, 4906-4910.

168 M. Qureshi, T. Shinagawa, N. Tsiapis and K. Takanabe, ACS Sustain. Chem. Eng., 2017, 5, 8079-8088.

169 T. Nishino, M. Saruyama, Z. Li, Y. Nagatsuma, M. Nakabayashi, N. Shibata, T. Yamada, R. Takahata, S. Yamazoe, T. Hisatomi, K. Domen and T. Teranishi, Chem. Sci., 2020, 11, 6862-6867.

170 R. Khare, A. Jentys and J. A. Lercher, Phys. Chem. Chem. Phys., 2020, 22, 18891-18901.

171 D. Spanu, A. Minguzzi, S. Recchia, F. Shahvardanfard, O. Tomanec, R. Zboril, P. Schmuki, P. Ghigna and M. Altomare, ACS Catal., 2020, 10, 8293-8302.

172 H. Lee, D. E. Yoon, S. Koh, M. S. Kang, J. Lim and D. C. Lee, Chem. Sci., 2020, 11, 2318-2329.

173 D. F. Zhang, H. Zhang, L. Guo, K. Zheng, X. D. Han and Z. Zhang, J. Mater. Chem., 2009, 19, 5220-5225.

174 Z. Xiong, Z. Lei, X. Chen, B. Gong, Y. Zhao, J. Zhang, C. Zheng and J. C. S. Wu, Catal. Commun., 2017, 96, 1-5.

175 M. Matsukawa, R. Ishikawa, T. Hisatomi, Y. Moriya, N. Shibata, J. Kubota, Y. Ikuhara and K. Domen, Nano Lett., 2014, 14, 1038-1041.

176 Y. Kuang, Q. Jia, G. Ma, T. Hisatomi, T. Minegishi, H. Nishiyama, M. Nakabayashi, N. Shibata, T. Yamada, A. Kudo and K. Domen, Nat. Energy, 2016, 2, 16191. 